\title{
A Mitochondrial Approach to Cardiovascular Risk and Disease
}

Caroline D. Veloso (1), Getachew D. Belew (1), Luciana L. Ferreira (1), Luís Grilo (1), John G. Jones (1), Piero Portincasa (2), Vilma A. Sardão (1), Paulo J. Oliveira (1)

(1) CNC - Center for Neuroscience and Cell Biology, UC-Biotech, University of Coimbra, Biocant Park, Cantanhede, Portugal

(2) Clinica Medica “A. Murri”, Department of Biomedical Sciences and Human Oncology, University of Bari “Aldo Moro” Medical School, Bari, Italy;

To whom correspondence would be addressed:

Paulo J. Oliveira, Ph.D,

CNC - Center for Neuroscience and Cell Biology, UC-Biotech, University of Coimbra, Biocant Park, 3060-197 Cantanhede, Portugal 
1 Abstract

2 Cardiovascular diseases (CVDs) are a leading risk factor for mortality worldwide and the

3 number of CVDs victims is predicted to rise through 2030. While several external

4 parameters (genetic, behavioral, environmental and physiological) contribute to

5 cardiovascular morbidity and mortality; intrinsic metabolic and functional determinants

6 such as insulin resistance, hyperglycemia, inflammation, high blood pressure and

7 dyslipidemia are considered to be dominant factors. High cardiac energy demand is

8 sustained by mitochondrial ATP production, and abnormal mitochondrial function has

9 been associated with several lifestyle- and aging-related pathologies in the developed

10 world such as diabetes, non-alcoholic fatty liver disease (NAFLD) and kidney diseases,

11 that in turn can lead to cardiac injury. In order to delay cardiac mitochondrial dysfunction

12 in the context of cardiovascular risk, regular physical activity has been shown to improve

13 mitochondrial parameters and myocardial tolerance to ischemia-reperfusion (IR).

14 Furthermore, pharmacological interventions can prevent the risk of CVDs. Therapeutic

15 agents that can target mitochondria, decreasing ROS production and improve its function

16 have been intensively researched. One example is the mitochondria-targeted antioxidant

17 MitoQ 10 , which already showed beneficial effects in hypertensive rat models. Carvedilol or antidiabetic drugs also showed protective effects by preventing cardiac mitochondrial oxidative damage. This review highlights the role of mitochondrial dysfunction in CVDs, also show-casing several approaches that act by improving mitochondrial function in the heart, contributing to decrease some of the risk factors associated to CVDs. 
1 Abbreviations

2 4HNE - 4-hydroxy-2-nonenal

$3 \mathrm{ACE}$ - Angiotensin-converting-enzyme

$4 \quad$ ADP - Adenosine Diphosphate

5 ADQI - Acute Dialysis Quality Initiative

6 AGEs - Advanced Glycation End Products

7 ATP - Adenosine Triphosphate

8 BMI - Body Mass Index

9 CD36-Cluster of Differentiation 36

10 CER - Ceramides

11 cGMP - Cyclic GMP

12 CKD - Chronic Kidney Disease

$13 \mathrm{CL}$ - Cardiolipin

14 CoQ10 - Co-enzyme Q10

15 CPT - Carnitine Palmitoyltransferases

16 CVDs - Cardiovascular Diseases

17 DAG - Diacylglycerol

18 DM - Diabetes Mellitus

19 Drp1 - Dynamin-related Protein

20 ECFCs - Endothelial Colony-forming Cells

21 ECM - Extracellular Matrix

22 eNOS - Endothelial Nitric Oxide Synthase

23 ETC - Electron Transport Chain

$24 \quad$ FAO - Fatty Acid $\beta$-oxidation

$25 \quad$ FFA - Free Fatty Acids 
1 GLUT4 - Glucose Transporter type 4

2 HDL - High Density Lipoprotein

3 HDL-C - High-density Lipoprotein Cholesterol

$4 \quad \mathrm{HF}$ - Heart Failure

$5 \quad$ HFD - High-fat Diet

6 Hsp - Heat Shock Protein

7 HUVECs - Human Umbilical Vein Endothelial Cells

8 IHD - Ischemic Heart Disease

$9 \quad \mathrm{IMM}$ - Inner Mitochondrial Membrane

10 IR - Ischemia-reperfusion

11 MAPK - Mitogen-activated Protein Kinase

$12 \mathrm{MCU}$ - Mitochondrial Ca2+ Uniporter

13 MFN - Mitofusin

14 MI - Myocardial Ischemia

15 MitoB - MitoBoronic Acid

16 MitoPerox - Mitochondria-targeted lipid peroxidation

17 MitoQ10 - Mitoquinone10

18 MitoSOX - Mitochondrial Superoxide indicator

MPC2 - Mitochondrial Pyruvate Carrier 2

$20 \mathrm{mPTP}-$ Mitochondrial permeability transition pore

21 mtDNA - Mitochondrial DNA

22 mtFAO - Mitochondrial Fatty Acid Oxidation

NAFLD - Non-alcoholic Fatty Liver Disease

24 NASH - Non-alcoholic Steatohepatitis

$25 \quad \mathrm{NO}$ - Nitric Oxide

NRF1 - Nuclear Respiratory Factor 1 
1 OMM - Outer Mitochondrial Membrane

2 OXPHOS - Oxidative Phosphorylation

$3 \quad$ PI3K - Phosphoinositide 3-Kinase

4 PPAR - Peroxisome proliferator-activated receptor

5 PUFAs - Polyunsaturated Fatty Acids

6 RAS - Renin-Angiotensin system

7 ROS - Reactive Oxygen Species

8 sdLDL - Small Dense Low-density Lipoproteins

$9 \quad$ SIRT - Sirtuin

10 SOD - Superoxide Dismutase

11 SR - Sarcoplasmic Reticulum

12 SS-31 - Elamipretide

13 STZ - Streptozotocin

14 TCA - Tricarboxylic Acid

15 Tfam - Mitochondrial Transcription Factor 1

16 TG - Triglycerides

17 Tmem135 - Transmembrane Protein 135

18 UCP - Uncoupling Protein

19 VDACs - Voltage-dependent Anion-selective Channel

20 WHO - World Health Organization

21 WT - Wild-type

22 


\section{Cardiovascular risk: definition and epidemiology}

2

3 Cardiovascular diseases (CVDs) accounts for one in every three deaths and is the leading

4 cause of mortality worldwide. It currently accounts for 17.5 million deaths annually, and

5 is predicted to increase to 23.6 million by 2030 [1]. It is also estimated by the World

6 Health Organization (WHO) that high blood pressure-related premature deaths will affect

$7 \quad 1.56$ billion people in 2025 [2]. Several diseases are included in the CVDs umbrella,

8 including coronary artery disease, atherosclerosis, thrombosis, strokes, rheumatic heart

9 disease, cardiomyopathy, ischemic heart disease (IHD) and heart failure, which

10 collectively affect around 128 million people worldwide [3] (Figure 1). Surprisingly, the majority of CVDs cases were reported in low- and middle-income countries [4].

CVDs etiology can be considered to be a mechanistic process that is triggered by cardiovascular risk factors that results in organ damage, organ failure and finally, death [5,6]. A risk factor can thus be linked to a particular physiological mechanism, which if intervened, can halt this pathophysiological process [7]. Therefore, identifying the risk factors that predispose an individual to CVDs through large-scale epidemiological studies is a critical first step [5,8,9]. Risk factors can be divided in two groups: modifiable risk factors, which comprise of individual behaviors that predispose to CVDs, and nonmodifiable risks, which cannot be altered (e.g., age, gender, genetics) [10] (Figure 1). Epidemiological studies have identified more than 60 risk factors which correlate with CVDs prevalence including high blood pressure, smoking, abdominal obesity, abnormal circulating lipids, insulin resistance/diabetes mellitus, stress, poor diet, and lack of regular physical activity, among other behavioral and environmental factors [11]. This huge number of variables makes it difficult to determine which risks are causal (e.g., high blood pressure) and which are associative (e.g., social environment). 
1 In $70 \%$ of cases, there is a clustering of individual risk factors which synergistically

2 increase overall CVDs risk from 4-fold with only 1 risk factor to 60-fold with 5 associated

3 risk factors [7]. Thus, $80 \%$ of IHD deaths and $70 \%$ of stroke-related deaths are associated

4 with small increases in different CVDs risk factors such as smoking, high Body Mass

5 Index (BMI), alcohol use, poor diet, physical inactivity, high blood pressure and high

6 serum cholesterol [12]. Interestingly, CVDs are most prevalent in individuals with modest

7 increases among several risk factors as opposed to those with a few risk factors that are

8 highly elevated [7].

9 The Framingham Heart Study was one of the first epidemiological studies focusing on

10 CVDs risk factors in a stable group of subjects, with their first volunteers recruited in 1948. This study played a central role in establishing of the association of CVDs development with smoking, high blood pressure, elevated serum cholesterol levels, and diabetes mellitus [8].

The three main causes of mortality in industrialized countries are tobacco use, high levels of circulating cholesterol and high blood pressure, which in combination represent a highprofile risk factor for CVDs. The same trend has also been recently observed in developing countries with the rise in obesity and high levels of circulating cholesterol [7]. Age-standardized CVDs rates were found to be associated with the establishment of several risk factors including BMI, and were inversely correlated with per-capita GDP. Thus, the highest rates were found in the poorer countries of central and eastern Europe and central Asia representing a 4-fold increase over those of wealthy countries [11]. Although risk factors are usually considered as gender-independent factors, the incidence of CVDs are more frequent in women than men. Additional risk factors for women include disorders related with pregnancy, such as gestational high blood pressure and gestational diabetes, endocrine disorders in women of reproductive age such as polycystic 
1 ovary syndrome and early menopause, increased abdominal obesity, and decreased levels

2 of circulating high density lipoprotein (HDL) post-menopause [13,14].

3 Obesity represents a major cardiovascular risk and is tightly linked to other risk factors

4 such as diabetes, metabolic syndrome, high blood pressure and dyslipidemia [15].

5 Increased BMI associated with other risk factors is responsible for nearly 9.7 million

6 CVDs deaths annually [11]. Obesity rates have increased in recent decades, and in 2016

71.9 billion individuals were overweight, representing one-third of the global adult

8 population $[16,17]$. Obesity represents a cluster of CVDs risk factors including high blood

9 pressure, dyslipidemia, and insulin resistance. Metabolic syndrome, which represents an

10 amalgamation of these risk factors, affects $20 \%$ to $30 \%$ of people worldwide and represents an increased CVDs risk of $70-90 \%[14,18]$.

In relation to obesity, dietary habits have a key role in individual predisposition for metabolic diseases as well as CVDs. Increased risk of CVDs was associated with specific diet profiles, including low intake of fruit and vegetables, high intake levels of trans fats, salt, processed meat, sugar, and other processed carbohydrates [11]. The magnitude of the diet effect in CVDs risk is probably exaggerated by the development of other risk factors, such as increases in BMI or blood glucose [18]. Other uncontrollable factors such as genetics as well as intrauterine and early life nutrition, can lead to the development of obesity and diabetes thereby increasing CVDs risk [19,20].

In a study standardized for genetic variations in alcohol metabolism, causal links between alcohol intake and development of IHD and stroke were identified [21]. Thus, the burden of CVDs is particularly high in countries where per-capita alcohol consumption is high such as Russia, Belarus and Moldavia as well as other ex-soviet countries [22]. 
1 Several other behavioral factors were correlated with the risk of CVDs including physical

2 inactivity, smoking and sleep time. Worldwide, 2.5 million CVDs deaths were associated

3 with physical inactivity [23]. The relationship between lack of physical activity and

4 increased CVDs risk seems clear, although the association becomes non-linear for people

5 with highly active lifestyles [24,25]. Physical activity has been shown to reduce the

6 mortality rate in people with pre-existing coronary artery disease [26]. Sleep times that

7 were either too short ( $<6$ hours) or too long ( $>9$ hours) were also associated with high

8 blood pressure and metabolic syndrome which are two well-established CVDs risk factors

$9 \quad[27,28]$.

10 Environmental risk factors were also observed for both short- and long-term air pollution exposure, which is related to IHD, stroke and heart failure (HF) incidence [29]. Reports estimate that globally, 2.5 million CVDs deaths are associated with the increase of particulate matter levels with major clusters of incidences in East and South Asia [23,31].

Alterations in these behavioral CVDs risk factors can result in a decrease in total CVDs risk. Cessation of smoking immediately starts to decrease the risk of CVDs, reaching the level for non-smokers within 10 years [30]. Also, normalization of elevated blood pressure and serum cholesterol levels immediately cut the risks of IHD and stroke, and if maintained for 5 years, the risks are reduced to that of the general population [11].

\section{Altered metabolism in cardiovascular risk}

\section{1 - Insulin resistance and cardiovascular risk}

22 As described above, hyperglycemia, inflammation and insulin resistance are risk factors for CVDs [33] (Figure 2). Insulin is a key regulator of cellular metabolism in various 
1 tissues, but this can be modulated by both physiological states, for example feeding and

2 fasting, and pathophysiological conditions such as Type 2 diabetes and fatty liver disease.

3 Insulin sensitivity refers to the efficacy of insulin in exerting its metabolic effects, while

4 its corollary, insulin resistance, refers to the degree by which these insulin actions are

5 attenuated - for example by disruption of the intracellular insulin signaling cascade.

6 Insulin resistance results in impaired glucose uptake, oxidation and conversion to

7 glycogen. Insulin resistance is also linked to hypertriglyceridemia and low levels of

8 circulating HDL. Moreover, insulin resistance exists in about $30 \%$ of subjects diagnosed

9 with high blood pressure [34], while one particular study showed a direct relation to

10 atherosclerosis [35]. Many studies have shown that insulin resistance is a good predictor

11 of CVDs [36,37]. A follow-up study of non-diabetic young subjects revealed that about $42 \%$ of myocardial infarctions could be avoided by improving insulin sensitivity [38].

Although several studies support the perception that CVDs are correlated to insulin resistance [39-45] some contrary results have also been reported. For instance, Kozakova et al. concluded that insulin sensitivity associated with CVDs risk in men, while proposing that the formation of atherosclerosis and plaque were independently related with fasting plasma glucose levels in women [46]. Hyperglycemia with insulin resistance produces alterations in various cellular and metabolic functions $[40,47,48]$ including dyslipidemia, endothelial dysfunction, high blood pressure, oxidative stress and cardiac metabolic alterations (Figure 2). Long chain fatty acid oxidation is the main pathway used for ATP (adenosine triphosphate) production in the adult myocardium; yet, the heart has the metabolic flexibility to oxidize other substrates according to their availability, including glucose, amino acids and lactate. Substrate transporters, such as CD36 (cluster of differentiation 36) for fatty acids and GLUT4 (Glucose transporter type 4) for glucose, have a high dynamic range in relation to transport rates hence the myocytes can 
1 experience large fluctuations in glucose and fatty acid availability depending on the

2 systemic supply of these substrates [49]. Normally about 50-70\% of myocardial ATP is

3 obtained by the oxidation of long-chain fatty acids, whereas less than $10 \%$ is derived from

4 glycolysis [49]. During injury, the heart changes its energetic substrate preference from

5 fatty acids to glucose. Insulin resistance impairs this metabolic flexibility and fatty acids

6 are imported as the main fuel source. Among other things, this can result in the

7 accumulation of lipids in the heart, which can lead to lipotoxicity [33,50]. In this context,

8 pharmacological modulation of CD36 and GLUT4 transporter activities could be a

9 strategy to restore glucose oxidation in the diabetic heart [49].

10 Moreover, insulin resistance is responsible for a decrease in endothelial nitric oxide (NO)

11 production while at the same time it leads to increased release of pro-coagulant factors

12 that leads to aggregation of platelets - which also promotes endothelial cell dysfunction.

13 During insulin resistance, the mitogen-activated protein kinase (MAPK) signaling 14 pathway remains active while the Phosphoinositide 3-kinase (PI3K) pathway is impaired, 15 resulting in an mitogenic effect in endothelial cells that eventually leads to atherosclerosis $16[51,52]$.

\subsection{Hyperglycemia in CVDs}

The high CVDs risk in type 2 diabetes patients, in which CVDs incidence is $2-8$ fold higher compared to normoglycemic subjects, lowers the life expectancy and accounts for the majority of fatalities globally [53,54]. One study reported that fasting blood glucose above $90 \mathrm{mg} / \mathrm{dl}$ is an independent predictor of artery atherosclerosis [55]. Impairment of glucose homeostasis, which is already present in subjects with impaired glucose tolerance 
1 and/or impaired fasting glucose (the so-called pre-diabetic conditions) could affect the

2 autonomic cardiac function leading to elevated CVDs risk [56].

3 Following the high excursions of plasma glucose levels that is characteristic of Type 2

4 diabetics, the hyperglycemic stress memory is retained even after control of blood glucose

5 levels has been restored [57,58]. Hyperglycemia and glucose fluctuations activate

6 inflammatory responses through endoplasmic reticulum stress and mitochondrial

7 dysfunction that later results in increased ROS (reactive oxygen species) generation,

8 which in turn causes cellular damage [59]. Hyperglycemia can also increase the

9 expression of pro-coagulant and pro-inflammatory factors, can increase the adhesion of

10 leukocytes to endothelial cells, can induce apoptosis and can impair the release of NO,

11 which in turn leads to endothelial dysfunction $[47,60]$.

12 The generation of advanced glycation end products (AGEs) that are non-enzymatic 13 alteration of lipids and proteins after exposure to increased glycemic conditions is another 14 damaging outcome of tenacious hyperglycemia [61]. Generally, AGEs accumulate in the wall of the vessel and affect the extracellular matrix (ECM) structural integrity that later leads to damage of the endothelium. This results in a decline in NO, contributing to the development of CVDs and microvascular complications such as retinopathy and nephropathy [62].

\subsection{Dyslipidemia in CVDs}

21 Impaired lipid homeostasis and storage within adipocytes secondary to factors such as insulin resistance leads to the progression of dyslipidemia. This is characterized by the lipid triad; low levels of high-density lipoprotein cholesterol (HDL-C), elevated plasma triglyceride levels, and the presence of small dense low-density lipoproteins (sdLDL), has 
1 been documented as a noticeable risk factor for CVDs [63-65] (Figure 2). In fact, the

2 prevalence of CVDs increases by $32 \%$ in men and $76 \%$ in women due to

3 hypertriglyceridemia $[66,67]$.

4 The accumulation of toxic lipid species (lipotoxicity), resulting from the surplus of lipids

5 in the cardiomyocyte alters the cardiac structure and cellular signaling. Thus, lipotoxicity

6 has been associated with several cellular signaling pathway disruptions mainly in

7 endoplasmic reticulum stress and mitochondrial dysfunction [33]. ROS, NO, ceramide,

8 phosphatidylinositol-3-kinase, diacylglycerol (DAG), ligands of Peroxisome

9 Proliferator-activated Receptor (PPAR) nuclear receptors and leptin are among the

10 mediators of these lipotoxic effects [68]. The excessive production of ROS resulting from

11 lipotoxicity leads to DNA, protein, and membrane damage, the latter causing stress and

12 damage within the endoplasmic reticulum. Furthermore, endoplasmic reticulum stress and oxidative stress both promote increases in intracellular $\mathrm{Ca}^{2+}[69]$. Excessive, nonregulated $\mathrm{Ca}^{2+}$ uptake by mitochondria can result in its overload in the matrix, and to the induction of mitochondrial permeability transition pore opening. This in turn results in cell apoptosis or necroptosis and mitochondrial dysfunction, processes that are implicated in the pathogenesis of diabetic cardiomyopathy [70,71].

\section{Mitochondrial roles in the cardiovascular system}

Mitochondria, which are the powerhouses of cardiac cells, sustain the energetic requirements of myocardial contractile work. These organelles regulate a vast range of processes, such as ATP production, intermediary metabolism and cell death [72-75]. Mitochondria are not static entities, but instead rather dynamic units that undergo fission and fusion cycles essential for their structural integrity [76]. Also, mitochondria possess their own independent genome that encodes 13 subunits of the mitochondrial oxidative 
1 phosphorylation (OXPHOS) complexes, multiple ribosomal and transfer RNAs, and

2 regulatory peptides such as the recently-identified MOTS-c and humanin [77,78].

3 Structurally, mitochondria have two separately and functionally distinct membranes that

4 delimitate two different mitochondrial compartments: the intermembrane space is

5 localized between the outer mitochondrial membrane (OMM) and the inner mitochondrial

6 membrane (IMM), while the matrix is the space within the IMM (Fig. 3). Although

7 initially considered part of the IMM, cristae are now considered membrane-delimited

8 independent structures which are rich in proteins responsible for ATP generation [79].

9 Located in the IMM is the respiratory chain where a series of redox reactions create a

10 proton electrochemical gradient through the pumping of protons to the intermembrane

11 space. The re-entrance of those protons to the mitochondrial matrix through ATP synthase

12 (or complex V) drives the phosphorylation of ADP (adenosine diphosphate) to ATP [80].

In cardiomyocytes, mitochondria are densely condensed, occupying around one third of cell volume, in order to respond to the high cardiac energy demand [81,82]. In fact, almost all the ATP ( $>90 \%)$ required for the contraction and relaxation loop is provided by mitochondrial oxidative phosphorylation and ATP needs to be constantly synthesized from ADP and inorganic phosphate [83,84]. Fatty acids are the preferred fuel for mitochondrial ATP production in the heart, yet the tissue can utilize many other substrates including carbohydrates, amino acids and ketone bodies depending on physiological conditions and substrate availability [85-87]. Physiologically, the mechanism of ATP production in a normal heart occurs usually in the following sequence: fatty acyl-CoA and pyruvate, resulting from fatty acids and glucose metabolism, respectively, are transported across the IMM and oxidized to acetyl-CoA. Pyruvate conversion is regulated by the pyruvate dehydrogenase complex, while fatty acyl-CoA undergoes fatty acid $\beta$ oxidation (FAO), and the resulting acetyl-CoA enters the TCA (tricarboxylic acid) cycle 
1 generating NADH and succinate that reduces the electron transport chain (ETC). The

2 majority of the ATP generated from this process is then hydrolyzed to fuel the contraction

3 machinery. ATP is required to dissociate actin from myosin [88], whereas the remaining

4 amount is mostly used by transmembrane ion pumps [86]. As such, mitochondria play a

5 key role in the maintenance of cytosolic $\mathrm{Ca}^{2+}$ concentration and modulation of muscle

6 contraction. Briefly, during contraction-relaxation cycles electric stimulation evokes the

7 influx of $\mathrm{Ca}^{2+}$ from the extracellular milieu to the cytosol and later from the sarcoplasmic

8 reticulum (SR). The increased concentration of cytosolic $\mathrm{Ca}^{2+}$ induces the contraction

9 mechanism (through the binding of $\mathrm{Ca}^{2+}$ to troponin $\mathrm{C}$ ) that is then followed by relaxation

10 when $\mathrm{Ca}^{2+}$ is pumped out of the cell or transported back to the SR. During this process,

11 mitochondria not only act as local buffers, but also the mitochondrial uptake of $\mathrm{Ca}^{2+}$ alters the activity of several mitochondrial enzymes resulting in the increase of respiratory rate and ATP production [89] (Figure 3). While the OMM is very permeable to $\mathrm{Ca}^{2+}$, mostly because of the presence of voltage-dependent anion-selective channel proteins (VDACs), the entrance of calcium into the matrix occurs essentially through the mitochondrial $\mathrm{Ca}^{2+}$ uniporter (MCU), driven by the mitochondrial membrane potential [90]. Despite the low affinity of MCU to $\mathrm{Ca}^{2+}$, the proximity of mitochondria to the SR and the formation of SR-mitochondria membrane contact sites leads to the transfer of $\mathrm{Ca}^{2+}$ directly from SR stores to the mitochondrial matrix [91-93], being then counteracted by the mitochondrial $\mathrm{Na}^{+} / \mathrm{Ca}^{2+}$ and $\mathrm{H}^{+} / \mathrm{Ca}^{2+}$ exchangers [94]. Given the importance of mitochondria to the cardiac activity and blood pumping, any decline of mitochondrial function is associated with impaired heart function [95]. The mitochondrial abnormalities may be associated with a reduced generation of ATP, increased production of ROS or even mitochondrialdriven cardiomyocyte death. 


\section{4. Role of mitochondrial alterations in cardiovascular risk}

2 This section will give some examples of specific conditions/pathologies in which an 3 association with altered cardiac mitochondrial function has been described.

\section{$4 \quad 4.1$ - Obesity}

5 Excessive fat accumulation in adipoctyes as well as in ectopic sites such as hepatocytes, 6 pancreas and myocytes, increases the risk of developing a number of patho-physiological 7 conditions, including CVDs. In an editorial comment for the Journal of the American 8 College of Cardiology [96], Dale Abel briefly reviewed possible mechanisms that may 9 contribute to cardiac alterations observed in obesity. The comment drew attention to the changes in cardiomyocyte metabolism, which include alterations in mitochondrial

11 function. His comment was based on a study developed by Niemann and co-workers, also

12 published in the same journal issue [97]. In this study of human adult right atrial cardiomyocytes, it was demonstrated that obesity disturbed both mitochondrial biogenesis and function, decreasing the mRNA levels for NRF1 (nuclear respiratory factor 1) and Tfam (mitochondrial transcription factor 1), two important transcription factors involved in mitochondrial biogenesis, and reducing the levels of mRNA and protein for ND6 (subunit of mitochondrial respiratory complex I, encoded in mitochondrial DNA) and NDUFB8 (another subunit of mitochondrial respiratory complex I, encoded in nuclear DNA). Furthermore, a decrease in the activity of mitochondrial respiratory complex I was also observed in atrial cardiac cells from obese patients. Those changes suggest that in obesity, mitochondrial function in cardiac cells appear to be compromised, which may be associated with an increased risk of HF. In fact, higher markers of oxidative stress were also observed in cardiac cells isolated from young obese as well as a $30 \%$ decrease in telomerase length - a sensitive indicator of 
1 cumulative oxidative stress. Furthermore, higher expression of the pro-apoptotic proteins

2 Bax and BCL-xS, the presence of cytochrome $\mathrm{c}$ in the cytosolic fraction of cardiac cells,

3 as well as an increase amount of cleaved caspase 9, suggest an activation of the

4 mitochondrial dependent apoptotic pathway in cardiac cells of obese individuals.

5 Mitochondria that were abnormally large size and devoid of cristae were also observed in

6 cardiac tissues harvested from obese mice [98]. The authors also observed higher levels

7 of 4-hydroxy-2-nonenal (4HNE), a marker of lipid peroxidation but low levels of

8 mitofusin (MFN) 2, an outer mitochondrial membrane GTPase required for the process

9 of mitochondrial fusion. This suggests a disruption in mitochondrial quality control

10 mechanisms which play a fundamental role in the maintenance of cardiac function [99].

11 In a rodent model, obesity led to a decreased expression of the mitochondrial SIRT3, which at least partly resulted in cardiac remodeling and dysfunction [100]. In other tissues, decreased SIRT3 expression and activity resulting from a high fat diet also led to increased acetylation of mitochondrial complex I, thereby reducing its activity [101]. Whether this same process occurs in the heart is not yet established.

Mitochondrial impairments were also observed in neonatal overfed rats, with decreased mitochondrial coupling efficiency and increased oxidative stress being observed [102]. These findings suggested that correct nutrition in critical periods of development are important in reducing the risk of cardiovascular problems.

Maternal obesity is associated with increased risk of cardiovascular dysfunction in the offspring. Ferey et al. demonstrated a transgenerational cardiac mitochondrial dysfunction [103], which was independent from maternal mitochondria inheritance. The authors observed that the offspring of obese mothers showed cardiac mitochondrial abnormalities, developing left ventricular hypertrophy. However, those effects observed 
1 in the male F1 generation were also transmitted to their descendants, suggesting

2 epigenetic nuclear alteration in germ cells of obese mothers.

3 In conclusion, changes in cardiac mitochondrial function and dynamics are observed in

4 obese individuals. Disruption in mitochondrial quality control mechanisms in obesity can

5 increase the risk of cardiac cell death and consequently HF, especially under stressful

6 conditions.

\section{4.2. Aging}

8 Aging is a natural process among living organisms, and is characterized by physiological

9 changes and cellular death (phenomenon of growth, decline and death). López-Otín et al.

10 described in 2013 nine hallmarks of aging: genomic instability, telomere attrition,

11 epigenetic alterations, loss of proteostasis, deregulated nutrient-sensing, mitochondrial dysfunction, cellular senescence, stem cell exhaustion, and altered intercellular communication [104]. Mitochondrial function has been related with aging-related consequences in the past decade [105-108], with a decrease in mitochondrial function accounting for alterations of different signaling and metabolic pathways. According to the free radical theory of aging there is an excessive production of ROS due to progressive mitochondrial dysfunction [109,110] leading to an increase of oxidative damage, although more recent data casted doubt of this model of aging, showing that physiological levels of ROS may not be harmful to mitochondria [105].

Since ROS production also occurs in mitochondria (especially at the mitochondrial respiratory chain complexes I and III), this organelle is more susceptible to oxidative damage with advancing age. Post-translational modifications, such as acetylation of mitochondrial proteins by mitochondrial sirtuins (SIRT3, SIRT4 and SIRT5), has been shown to be involved in the pathogenesis of cardiac diseases such as myocardial 
1 infarction (ischemia-reperfusion (IR)) and HF [111,112]. SIRT3 is the main $\mathrm{NAD}^{+}-$

2 dependent mitochondrial deacetylase and regulates mitochondrial bioenergetics and

3 metabolism, contributing to the prevention of the redox stress and cell aging [111]. SIRT3

4 is also responsible for the regulation of the $\mathrm{mPTP}$ (mitochondrial permeability transition

5 pore). MPTP opening is related with different pathologies and with the release of

6 proapoptotic factors. SIRT 3 can inhibit mPTP opening, via deacetylation of cyclophilin

7 D- a key component of mPTP. This cascade of events will eventually reduce oxidative

8 stress and slow down cardiac aging [113].SIRT3 KO mice showed decreased expression

9 of angiogenic growth factors, endothelial dysfunction and coronary microvascular

10 dysfunction post-myocardial ischemia (MI), leading to impaired cardiac recovery. On the

11 other hand, overexpression of SIRT3 protected heart from MI [114]. In addition to SIRT3,

12 the mitochondrial $\mathrm{p} 66^{\text {Shc }}$ adaptor protein has been linked to aging and CVDs $[115,116]$.

13 In a knockout mouse model, $\mathrm{p} 66^{\text {Shc }}$ genetic deletion induced a decrease of ROS levels and at the same time resulted in a prolonged lifespan [117]. With advanced age, endothelial dysfunction of the basilar artery is reduced in $\mathrm{p} 66^{\text {Shc-l- }}$ mice comparing with age-matched WT mice due to a lower ROS production, thus reducing a risk factor for $\underline{\text { stroke }[118] . \text { Also, hypertensive Wistar Kyoto rats presented a higher activation of } \mathrm{p} 66^{\text {Shc }}}$ $\underline{\text { in isolated aortic endothelial cells, compared to normotensive ones [119]. Likewise, }}$ knockout mice have smaller strokes after IR brain injury [120]._Alterations of transmembrane protein 135 (Tmem135) gene expression, a regulator of mitochondrial dynamics [121], have also been found to be related with heart abnormalities [122]. Mitochondrial size in cardiomyocytes is decreased in transgenic mice overexpressing Tmem135 compared to wild-type (WT) mice. Moreover, transgenic hearts for Tmem135 shows similar gene expression profiles and pathologies to aged hearts such as hypertrophy and collagen accumulation, indicating fibrosis [123]. It is known that some 
1 cardiomyopathies may be attributed to the accumulation of mitochondrial DNA (mtDNA)

2 damage [124,125], which can lead to defects in OXPHOS enzyme genes and decreased

3 apoptotic threshold [126]. In an early study, Matthews et al. correlated the 3243 A to G

4 mtDNA mutation to an increase in cardiomyopathy incidence [127]. More recently,

5 Tranah et al. (2018) quantified the 3243 A to $\mathrm{G}$ mtDNA mutation in an aged population,

6 showing that some age-related diseases can be attributed to the accumulation of mtDNA

7 damage [128].

8 Although aging is a natural process, its progression is linked to a higher incidence of

9 CVDs. Cardiac mitochondrial function deteriorates during the aging process, which limits

10 not only the capacity of the heart to withstand second stresses, but also reduces cardiac

11 contractile performance not only because of lack of necessary ATP, but also because of

12 imperfect regulation of cytosolic calcium and redox balance.

\section{3 - Diabetes}

14 Although the increased risk of $\mathrm{HF}$ during diabetes is multifactorial, changes in 15 mitochondrial function appear to have determinant role $[129,130]$. In the diabetic heart, a metabolic shift towards more active FAO is observed, which is associated with a

17 reduction in cardiac efficiency [130-133]. Changes in acetylation/deacetylation of mitochondrial proteins have been considered key regulators in mitochondrial metabolism shift in diabetic heart [111]. For example, hyperacetylation of mitochondrial pyruvate carrier 2 (MPC2) is observed in a transgenic mouse model for type I diabetes, decreasing the pyruvate transport in heart mitochondria and contributing to the metabolic changes [134], since it decreases the flux of the Krebs cycle and feeding of electrons to the mitochondrial respiratory chain. 
1 Cardiac contractile dysfunction and an impaired mitochondrial function was observed in

2 the heart of SIRT3 knockout mice, when compared to their wild type counterparts. In line

3 with the absence of SIRT3, hyperacetylation of several proteins of mitochondrial energy

4 catabolic pathways have been identified as a major cause for the observed cardiac

5 dysfunction [135]. The role of SIRT3 for the development of diabetes-associated

6 cardiomyopathies appears to be determinant. However, how SIRT3 activity is decreased

7 during hyperglycemia or insulin resistance is not entirely clear. A reduction in the

8 expression and activity of SIRT3 was observed in fetal endothelial colony-forming cells

9 (ECFCs) and human umbilical vein endothelial cells (HUVECs) isolated from cord and

10 cord blood of gestational diabetes pregnancies, suggesting a possible mechanism for the

11 long-term cardiovascular complications observed in the offspring of gestational diabetes

12 pregnancies [136]. Thus, hyperacetylation of enzymes involved in mitochondrial metabolism appears to contribute for diabetes-associated cardiac dysfunction.

p66 $6^{\text {Shc }}$ is also linked to cardiovascular dysfunction and oxidative stress markers that occur

in diabetes, and can be a powerful therapeutic target to vascular complications that come

with this pathology $[137,138]$.

17 Changes in lipid profile, with an increased production of toxic lipids species, reduction in polyunsaturated fatty acids (PUFAs) and downregulation of several phospholipid species were observed in cardiac tissue of C57BL/6 male mice injected intraperitoneally with a single dose of $150 \mathrm{mg} / \mathrm{kg}$ body weight of streptozotocin (STZ) [139]. An increased expression of gene involved in fatty-acid degradation and increased peroxisomal beta oxidation as well as abnormalities in mitochondrial structure and decreased ATP levels were also observed in cardiac tissue of animals treated with STZ. The authors suggested that those abnormalities in mitochondrial structure and decreased ATP levels could be related with the changes in phospholipid profile. Interesting, the authors also found an 
1 increase in mRNA levels of mitochondrial uncoupling protein 3 (UCP3), which was

2 associated with an increased in mitochondria uncoupling and decreased of ATP levels.

3 However, another study demonstrated a down-regulation in mitochondrial UCP3 in

4 myocardial tissue from animal models of insulin resistance and type 2 diabetes, impairing

5 mitochondrial fatty acid oxidation (mtFAO) and contractile recovery after an IR episode

6 [140]. These contradictory results may be related to the different animal models used in

7 the two studies, indicating that different mechanisms may be involved in diabetes-

8 associated cardiomyopathies, depending on the individual genetic profile and diabetes-

9 induced stimulus.

10 Notably, a decreased tolerance to the induction of the calcium-induced mitochondrial

11 permeability transition has also been observed for hearts of diabetic animals, which can

12 promote the loss of cardiomyocytes by apoptosis or necroptosis [141-143]. Augmented

13 induction of the mitochondrial permeability transition pore can disrupt the role

14 mitochondria have in calcium handling and ROS generation in the myocardium,

15 contributing to contractile disruption [144].

$16 \underline{\text { In OVE26 mice, cardiac dysfunction was observed as early as } 3 \text { months of age. This }}$ mouse model is built around a 5-fold increase in calmodulin expression in beta cells due to a calmodulin minigene driven by the rat insulin promoter which leads to beta cells apoptosis and consequent hyperglycaemia by $2-3$ weeks of age [145-147]. In this model $\underline{\text { a large decrease in mitochondrial respiration when stimulated with non-FA substrates was }}$ observed, which is probably a result of mitochondrial dysfunction resulted from the accumulation of incomplete FA oxidation molecules [148,149]. By using the AKITA Ins2+/- mouse, compromised cardiac mitochondrial function without alterations in cardiac efficiency or in insulin resistance was also previously observed $[150,151]$. This model is characterized by a mutation in insulin 2 gene which 
1 impairs protein folding resulting in a progressive loss of beta cells similarly to what occurs in T1D [152,153]. Cardiac lipid metabolism as well as lipid phenotype is affected

3 in this model. An increase in fatty acyl - CoA, ceramides, DAG and TAG was observed

4 in 3 months AKITA mice, a time at which lipid droplets could be observed in the heart.

5 which are more pronounced at 6 months of age [154]. Furthermore, increased

6 mitochondrial FA oxidation was described with concomitant increase in mitochondrial

$7 \quad$ FA oxidation proteins, ATGL, PDK4, CD36 and FATP expression $[150,151,154,155]$.

8 In conclusion, mitochondrial metabolism appears to have a determinant role for the

9 development of cardiomyopathies induced by diabetes. The shift towards FAO in 10 detriment to glycolysis results in accumulation of toxic lipids intermediates and alteration 11 in cellular lipid profile, having a negative effect on mitochondrial function. Since mitochondria are the main producer of ATP in cardiac cells, any damage in this organelle compromises viability and function of those cells and consequent performance of the heart.

\subsection{Non-alcoholic fatty liver disease (NAFLD)}

The abnormal accumulation of lipids, mainly triglyceride, in the liver in the absence of (or low) alcohol ingestion is known as NAFLD [156]. NAFLD can evolve to nonalcoholic steatohepatitis (NASH), fibrosis, cirrhosis and liver failure, and hepatocellular carcinoma [157]. NAFLD frequency is growing worldwide and is related to the increase of cardiovascular risk and other metabolic syndromes such as insulin resistance and obesity [158-160]. Cardiovascular disease is one of the most common cause of mortality in NAFLD [161] and some authors concluded that cardiac dysfunction is also associated with visceral fat accumulation - itself frequently associated with NAFLD [162]. Mitochondria are present in a large number in hepatocytes ranging from 500 to 4000 per 
1 hepatocyte [163] and mitochondrial dysfunction has been related to the progression of

2 NAFLD (Figure 4), since those organelles lose the ability to oxidize fatty acids, increasing

3 their accumulation in the hepatocyte [163-165]. Mitochondria play a key role in the

4 maintenance of fat homeostasis, but also in the maintenance of ROS levels that can trigger

5 lipid peroxidation, cytokine overproduction and apoptosis if ROS production is

6 uncontrolled [166]. Hepatocyte free fatty acids (FFA) undergo mtFAO regulated by

7 carnitine palmitoyltransferases (CPT) I and II producing ROS (Figure 5), so the increase

8 of FFA in NAFLD will lead to oxidative stress and inflammation [167]. As described

9 previously, the heart obtains most of its chemical energy from FAO, and a state of cardiac

10 lipotoxicity can be reached when there is increased fat deposition in cardiomyocytes as

11 well as in the epicardial adipose tissue surrounding the heart [168]. A 2016 study showed that increased epicardial adipose tissue volume and NAFLD are associated with the presence of the metabolic syndrome [169], while a more recent study showed that epicardial adipose tissue is strongly associated with NAFLD and other cardiovascular risk factors [170]. To our best knowledge, there are no reports that have presented evidence linking alterations in epicardial adipose tissue mitochondrial activity with altered contractile performance of the myocardium.

Mitochondrial dysfunction has been related to several cardiac abnormalities in models of high-fat diet (HFD). Recently, Nie H. et al observed a reduction in the activity of cardiac mitochondrial complex I with a reduction of ATP production and oxygen consumption in obese-mice. Along with these features, mice presented cardiac hypertrophy and severe cardiac structural disorders [171]. Those results were supported by other authors using other rodent models, together with the observation of morphologic changes in mitochondria and a reduction in mtDNA copy number in HFD group, as well as reduced mitochondrial fusion genes (MFN1, MFN2 and OPA1) and enhanced mitochondrial 
1 fission genes (DRP1 and FIS1) [172]. Cardiac mitochondrial lipid profile was also found

2 to be altered in obese when compared to their non-obese counterparts. Cardiac

3 mitochondrial triglycerides (TG), independently associated with myocardial fibrosis,

4 were increased in HFD-fed rats with myocardial infarction, as opposed to overall cardiac

5 mitochondrial cardiolipins (CLs) whose levels were reduced [173]. Cardiac ceramides

6 (CER) are related to cardiovascular events [174], and were significantly increased in

7 mitochondria of heart from rats HFD with MI [173]. Murray et al. showed that rats with

8 failing hearts presented higher levels of UCP3 and high circulating FFA concentrations

9 [175]. The cardiac tissue overexpresses UCP2 and 3 as a mechanism against lipotoxicity 10 and excessive ROS production [176], which can both act as a potential mechanism and 11 therapeutic target for NAFLD [177]. However, a study in UCP2 knock-out mice exposed 12 to an obesogenic stimulus did not reveal any differences on severity of NAFLD 13 comparing with mice expressing UCP2 [178].

14 The published data so far indicates that NAFLD is associated with cardiovascular 15 alterations, which involve increased accumulation of fat in cardiomyocytes while at the same time mitochondrial activity is decreased. Among other things, contractile

17 perturbances can be a consequence of this disarranged cardiac metabolic state.

\section{5 - Kidney diseases}

The dynamic interplay between heart and kidney dysfunction is described under the umbrella term named cardio-renal syndrome. Although not a new concept [179], cardiorenal syndrome become more recognized after the consensus conference by the Acute Dialysis Quality Initiative (ADQI), where a definition and a classification in 5 types were defined [180-182]. The consensus definition for cardio-renal syndromes was termed as: "disorders of the heart and kidneys whereby acute or chronic dysfunction in one organ 
1 may induce acute or chronic dysfunction of the other" [180]. Cardio-renal syndromes

2 were also classified in five types: Acute cardio-renal syndrome (type 1), where an acute

3 HF induces an acute kidney injury; Chronic cardio-renal Syndrome (type 2), where

4 chronic cardiac dysfunction induces progressive kidney injury; Acute reno-cardiac

5 syndrome (type 3), where an acute kidney dysfunction induces heart injuries; Chronic

6 reno-cardiac syndrome (type 4), where chronic kidney dysfunction induces progressive

7 HF; and Secondary cardio-renal syndromes (type 5), where systemic disorders, such

8 sepsis, infections, drugs or toxins, lupus, diabetes or other chronic inflammatory

9 conditions, induces simultaneous injuries of the heart and kidneys. Both the kidney and

10 heart are high energy-demanding organs, hence mitochondria play in both organs

11 essential roles. Bigelman and co-workers [183] demonstrated that chronic kidney disease

12 (CKD) induced changes in the structure of cardiac mitochondria, including increased volume indicative of mitochondrial swelling (Figure 5). Furthermore, increased cytochrome c leakage to the cytosol and cleavage of PARP-1 suggested mitochondrial dependent apoptotic pathway activation. Changes in CL remodeling and loss of its content was observed in cardiac tissue from female domestic pigs with renal artery stenoses and consequent renovascular high blood pressure [184]. CL is a phospholipid found exclusively in mitochondrial inner membrane, with a conical structure that allows optimal assembly of the supercomplexes of the mitochondrial ETC within the mitochondrial cristae curvature [185]. Thus, changes in CL contents and remodeling disturb mitochondrial function and increase oxidative stress and apoptosis in cardiac cells leading to myocardial injury. Fragmentation of cardiac mitochondria were also found in 8-week-old male C57BL/6 mice, undergoing bilateral renal artery clamping for $30 \mathrm{~min}$ to induce renal IR injury [186]. Associated with mitochondrial fragmentation, apoptosis of cardiac cells and cardiac dysfunction was also observed. Increased levels of dynamin- 
1 related protein 1 (Drp1), a protein that regulates the mitochondrial fission, was observed

2 in the heart of C57BL/6 mice 24 hours after renal IR injury. Interesting, inhibition of

3 Drp1 prevented mitochondrial fragmentation, cardiac cells apoptosis and cardiac

4 dysfunction [186], suggesting that inhibition of cardiac mitochondrial fission could in

5 theory have a therapeutic effect during acute kidney injuries.

6 As a conclusion, changes in mitochondrial dynamics and function are observed in cardiac

7 tissue after acute or chronic kidney injury and may be the bridge in the cardio-renal

8 syndrome. Thus, protecting mitochondrial function may be a good strategy to prevent

9 cardiac injuries induced by kidney dysfunction.

\section{Improving cardiac mitochondrial function to decrease cardiovascular risk}

\subsection{Physical activity}

Regular physical activity provides irrefutable benefits for human health and it has a wellestablished relationship with cardiorespiratory fitness and protection (Figure 6) [187189]. In adults, recommendations from the WHO indicate that a minimum of $150 \mathrm{~min}$ of moderate-to-vigorous physical activity should be performed through the week, while for children and adolescents this amount should be significantly greater ( $>60 \mathrm{~min}$ per day) $[190,191]$. In a large population study (> 55,000 adult man), around 10 min running per day at a slow speed was already associated with reduced risk of death and CVDs [192]. However, the challenging modern lifestyle progressively reduced the time dedicated to physical activity and the rising of physical inactivity has been identified as the fourth leading risk factor for global mortality [193,194]. IR insults are particularly damaging to the myocardium [195-197]. Oxygen deprivation, as a result of obstructed coronary artery, rapidly unbalance the bioenergetics supplies. However, the posterior reoxygenation by 
1 reperfusion can be even more damaging because of a panoply of pathological

2 mechanisms, especially the dramatically increase in ROS production [196]. The strategy

3 of preconditioning to protect IR hearts has been extensively studied, and was first noted

4 when brief and repetitive non-injurious ischemic episodes, before a subsequent long last

5 ischemia, decreased heart injury caused by IR [198]. Similarly, cardiac preconditioning

6 by exercise training (considered a more intense stimulus than physical activity) protects

7 the heart against IR. During resistance exercise there is a drop in the blood flow to the

8 tissues that may cause temporary ischemia. These bouts of non-deleterious IR episodes

9 may exert protective effects on the vasculature. This strategy has been successfully

10 applied in rodent models [199-202]. In humans, both younger (25 \pm 2 years) [203] and

11 older (> 57 years) [204] individuals following lifelong exercise trainings have more tolerance against endothelial IR compared with sedentary participants.

During physical activity or exercise the cardiovascular system needs to adapt in order to pump adequate amount of blood to exercising and non-exercising tissues. Thus, mitochondria are required to produce a larger amount of ATP to fuel the increased workload. A number of studies have focused on identifying the mitochondrial parameters that are remodeled by exercise training, even though the underlying mechanisms are still only partially understood [205-207]. Mitochondria isolated from exercised animals are less sensitive to apoptotic stimuli [208,209] and some authors observed improvements in cardiomyocyte $\mathrm{Ca}^{2+}$ cycling (and hence contractile function) [210] as well as decreased susceptibility to $\mathrm{Ca}^{2+}$-induced mPTP opening due to an increased capacity to accumulate $\mathrm{Ca}^{2+}$ [211]. Moreover, it is well known that during heart disease energy metabolism switches from FAO to glycolysis. Kavazis et al. [207] observed that following repeated bouts of endurance exercise, several proteins involved in FAO were increased in rat cardiac mitochondria. Regarding antioxidant defenses, there is a lack of consensus on 
1 their role in conferring protection during exercise [212]. Exercise training was found by

2 many to increase mitochondrial SOD (superoxide dismutase) 2 activity [208,209,213],

3 whereas inconsistent results were observed regarding cytosolic SOD1, glutathione

4 peroxidase and catalase activity, probably because of the diversity of training protocols

5 and different methodologies (enzyme activity measured from heart homogenates $v s$

6 isolated mitochondria) [209,212,214]. The heat shock protein (Hsp) system, another cell

7 defense mechanism against oxidative stress, was also involved in the exercise-related

8 beneficial effects. In particular, Hsp70, associated with myocardial protection [215], was

9 shown to be increased in rats after a 8-weeks training, mitigating the age-dependent

10 decline of Hsp70 abundance [216]. In another 8-weeks aerobic exercise study, rats

11 posteriorly subjected to myocardial infarction-induced HF presented signs of improved

12 cardiac function (restored mitochondrial oxygen consumption, increased $\mathrm{Ca}^{2+}$-induced mPTP and reduced $\mathrm{H}_{2} \mathrm{O}_{2}$ release) and improved cardiac protein quality control [205].

Also, moderate intensity exercise stimulates the synthesis of NO, an important regulator of vascular tone and blood flow [217], by increasing and activating the endothelial nitric oxide synthase (eNOS) [218]. NO regulates PGC-1 $\alpha$ expression via the generation of cyclic GMP (cGMP) and induces the expression of several members of the mitochondrial ROS detoxification system [219,220]. In addition, PGC-1 $\alpha$-dependent mitochondrial biogenesis also seems to be regulated by musclin, an exercise-responsive myokine with homology to natriuretic peptides [221]. Importantly, most of the studies are based on the effects of regular physical activity on the cardiovascular system. Acute episodes of physical activity have been considered to increase the incidence of myocardial infarction, especially in sedentary individuals [222]. Overall, evidence suggests that both short-term (few days) and long-term (weeks to months) exercise improve myocardial tolerance to IR [223]. 


\section{$2 \quad 5.2$ - Pharmacological interventions}

3 It is unquestionable that the lives of millions of people in the world have been improved

4 by the advances in primary and secondary prevention of CVDs [224]. Although there are

5 some controversial results, a number of therapeutic approaches have been studied and

6 validated, including lifestyle interventions (diet and physical exercise) and medications

7 that target oxidative stress mechanisms, inflammation, cardiac hypertrophy, apoptosis

8 and fibrosis (Figure 6) [225-227]. Molecules that can target mitochondria and decrease

9 mitochondrial dysfunction have been developed in recent years [228]. Interestingly, the

10 objective of many groups is to discover novel therapeutic agents that target mitochondrial

11 function and excessive ROS production associated with the development of

12 atherosclerosis, IR injury, diabetes mellitus, high blood pressure and HF [229].

13 Accordingly, several studies in both animal and human have revealed that co-enzyme $\mathrm{Q}_{10}$

$14\left(\mathrm{CoQ}_{10}\right)$ present in the inner membrane of mitochondria - thus vital for ATP production shows anti-thrombotic and antioxidant properties, improvement of high blood pressure and hyperglycemia-induced injury [230]. The study performed in hypertensive rat models have shown that $\mathrm{CoQ}_{10}$ supplementation improved endothelial function and cardiac hypertrophy [231]. Moreover, administration of $\mathrm{CoQ}_{10}$ in humans was shown to relieve the muscle pain derived from statin-caused rhabdomyolysis [232], although it is still not clear whether CVDs would all benefit from $\mathrm{CoQ}_{10}$ supplementation, although it has been proposed to be an adequate treatment option against mitochondrial dysfunction during high blood pressure and HF in humans [233].

Additionally, administration of antioxidant molecules linked to lipophilic molecules which selectively target the mitochondria have served as another alternative new approach [234,235]. For instance, MitoQ ${ }_{10}\left(\right.$ Mitoquinone $\left._{10}\right)$ was tested in hypertensive 
1 rat models and showed improvements on endothelial NO bioavailability and blood

2 pressure [231]. Moreover, MitoQ 10 treatment has shown beneficial against high blood

3 pressure [236], cardiac hypertrophy [231] and IR injury [235], although over-dosage can

4 potentially disrupt the function of mitochondria [237]. In addition, a range of Mito-

5 compound probes including MitoB (MitoBoronic Acid) [238], MitoSOX (mitochondrial

6 superoxide indicator) [239] and MitoPerox (mitochondria-targeted lipid peroxidation)

7 probe [240] have been developed in this series. MitoSOX and synthetic SOD molecules

8 (EUK-8 and EUK-134) have shown mitochondrial antioxidant actions against IR injury

9 [241,242]. In a different strategy, the $\beta$-blocker carvedilol has shown beneficial

10 antioxidant and anti-apoptotic properties in HF patients [243]. Interestingly, we and

11 others have already shown that carvedilol prevents cardiac mitochondrial oxidative

12 damage in different model systems [244-250], in part by inhibiting the mitochondrial permeability transition pore.

Importantly, angiotensin-converting-enzyme (ACE) inhibitors and angiotensin receptor-

II blockers that targets the activation of Renin-Angiotensin system (RAS) have also shown beneficial effect against mitochondrial dysfunction [251]. For instance, dogs treated with captopril showed increased cardiac mitochondrial biogenesis, which can be effective to inhibit mitochondrial disruption upon different of internal and external cellular stresses [252,253].

Statins are among the drugs which show a significant pleiotropic effect besides their known activity of inhibiting the synthesis of endogenous cholesterol [254,255]. Statins have been shown to act on mitochondria in different tissues to decrease oxidative stress [256]. Moreover, Parihar et al. showed in rats that the activity of mitochondrial NO synthase, cytochrome c release and lipid peroxidation were reduced by atorvastatin and simvastatin [257]. 
1 Antidiabetic drugs are among the alternative therapeutic agents involved in CVDs

2 treatment by improving mitochondrial function. For instance, metformin which is the

3 primary therapeutic option for newly-diagnosed type 2 diabetes mellitus, has displayed

4 an overall sparing effect on the cardiovascular system [258]. Specifically, studies have

5 indicated that metformin plays a vital role in reducing mitochondrial ROS production,

6 enhancing antioxidant enzymes activity and decreasing inflammation implicated in IR

7 injury [259]. Furthermore, thiazolidenediones are another class of antidiabetic drugs that

8 activate $\operatorname{PPAR} \gamma$, thereby improving lipid storage in adipocytes and diminishing ectopic

9 lipid pools. These have been shown to inhibit atherosclerosis development in animal 10 models $[260,261]$.

11 Alternatively, the novel therapeutic drug, Elamipretide (SS-31), is a water-soluble tetrapeptide that boosts energy production in mitochondria. It selectively binds to CL, conserves the mitochondrial cristae structure and enhances OXPHOS function [262]. Remarkably, in advanced HF dog models, SS-31 enhanced the enlargement and function of the left ventricle, decreased the formation of ROS, and resulted in improved plasma natriuretic peptides and inflammation biomarkers [263]. A randomized trial study in

17 humans with HF have shown similar results [264]. In rats, SS-31 improved oxidative stress and delayed cardiac remodeling and post myocardial infarction inflammation [265].

In conclusion, a number of therapeutic options including the ones listed above have been tested for protecting mitochondrial function in individuals which have one or more risk factors, and that show early signs of CVDs.

\section{Conclusions and Future directions}

Because the myocardium is very dependent on mitochondrial function, not exclusively due to the role of those organelles in energy production, it is not surprising that CVD have a strong mitochondrial component. We exemplified here some risk factors (obesity, 
1 aging, diabetes, kidney disease) that are related with decreased cardiac mitochondrial

2 function. Regardless of the mechanisms involved, the end result is a loss of mitochondrial

3 ability to produce ATP, to regulate calcium and other ion fluxes in the cell, to control the

4 generation of ROS (often leading to increased ROS generation which is not counteracted

5 by an effective antioxidant network), and to properly control cell death. Loss of

6 contractile activity can ensue because of energy supply failure leading to pump failure.

7 Preventing this to occur is achieved through control of modifiable risk factors, which

8 commonly involve moving towards healthy lifestyles. The present review presents

9 physical activity and mitochondria-directed strategies as two possible interventions that

10 could not only manage risk factors but act directly on the mediator of tissue dysfunction.

11 Still, there are many open challenges, including understanding how cardiac mitochondria

12 respond to one of multiple risk factors, how to measure cardiac mitochondrial function in

13 a non-invasive manner in order to predict disease staging or therapeutic intervention success, and the successful development and entry in the market of novel single or mixed interventions, which can act in multiple levels, not only lowering modifiable risk factors, but also directly acting to decrease mitochondrial disruption, especially resulting from increased ROS production. In the near future, it would also be interesting to understand the role of mitochondrial dynamics and mitophagy in the homeostasis of the cardiovascular system and cardiomyocyte quality control and repair, as well as the interface between metabolic dysfunction and diverse signaling pathways implicated in nuclear transcription regulation and mitochondrial biogenesis. Furthermore, non-invasive $\underline{\text { measurement of "live" cardiac mitochondrial metabolism could be used to anticipate the }}$ progression of CVDs provided that early and sensitive markers of mitochondrial $\underline{\text { dysfunction are identified. }}$ 


\section{7. Acknowledgements}

2 Work in the authors laboratory is funded by FEDER funds through the Operational

3 Programme Competitiveness Factors - COMPETE and national funds by FCT -

4 Foundation for Science and Technology (grants PTDC/DTP-FTO/2433/2014, POCI-01-

5 0145-FEDER-016659, POCI-01-0145-FEDER-007440). GB receives funding from the

6 European Union's Horizon 2020 Research and Innovation programme under the Marie

7 Skłodowska-Curie Grant Agreement No. 722619 (FOIE GRAS).

8

9 
1

2

3

4

5

6

\section{References}

[1] World Health Organization. Global health estimates: deaths and causes, age, sex and country. 2014.

[2] Kearney PM, Whelton M, Reynolds K, Muntner P, Whelton PK, He J. Global burden of hypertension: Analysis of worldwide data. Lancet. 2005 Jan;365(9455):217-23.

[3] Celermajer DS, Chow CK, Marijon E, Anstey NM, Woo KS. Cardiovascular disease in the developing world: prevalences, patterns, and the potential of early disease detection. J Am Coll Cardiol [Internet]. 2012 Oct 2;60(14):1207-16. Available from: http://www.ncbi.nlm.nih.gov/pubmed/22858388

[4] Mathers CD, Salomon JA, Ezzati M, Begg S, Hoorn S Vander, Lopez AD. Sensitivity and Uncertainty Analyses for Burden of Disease and Risk Factor Estimates [Internet]. Global Burden of Disease and Risk Factors. The International Bank for Reconstruction and Development / The World Bank; 2006. Available from: http://www.ncbi.nlm.nih.gov/pubmed/21250370

[5] Dzau VJ, Antman EM, Black HR, Hayes DL, Manson JE, Plutzky J, et al. The cardiovascular disease continuum validated: Clinical evidence of improved patient outcomes: Part I: Pathophysiology and clinical trial evidence (risk factors through stable coronary artery disease). Vol. 114, Circulation. 2006. p. 2850-70.

[6] Ezzati M, Vander Hoorn S, Lawes CMM, Leach R, James WPT, Lopez AD, et al. Rethinking the "diseases of affluence" paradigm: Global patterns of nutritional risks in relation to economic development. Novotny T, editor. PLoS Med. 2005 May;2(5):e133.

[7] Dahlöf B. Cardiovascular Disease Risk Factors: Epidemiology and Risk Assessment. Am J Cardiol. 2010 Jan;105(1):3A-9A.

[8] De Backer G. Epidemiology and prevention of cardiovascular disease: Quo vadis? In: European Journal of Preventive Cardiology. 2017. p. 768-72. 
1 [9] Balakumar P, Maung-U K, Jagadeesh G. Prevalence and prevention of cardiovascular disease and diabetes mellitus. Vol. 113, Pharmacological Research. 2016. p. 600-9.

[10] Tzoulaki I, Elliott P, Kontis V, Ezzati M. Worldwide Exposures to Cardiovascular Risk Factors and Associated Health Effects: Current Knowledge and Data Gaps. Circulation. 2016 Jun;133(23):2314-33.

[11] Ezzati M, Hoorn S Vander, Rodgers A, Lopez AD, Mathers CD, Murray CJL, et al. Estimates of global and regional potential health gains from reducing multiple major risk factors. Lancet (London, England). 2003 Jul;362(9380):271-80.

[12] Mahmood SS, Levy D, Vasan RS, Wang TJ. The Framingham Heart Study and the epidemiology of cardiovascular disease: A historical perspective. Vol. 383, The Lancet. 2014. p. 999-1008.

[13] Appelman Y, van Rijn BB, ten Haaf ME, Boersma E, Peters SAE. Sex differences in cardiovascular risk factors and disease prevention. Atherosclerosis. 2015 $\mathrm{Jul} ; 241(1): 211-8$.

[14] Pucci G, Alcidi R, Tap L, Battista F, Mattace-Raso F, Schillaci G. Sex- and genderrelated prevalence, cardiovascular risk and therapeutic approach in metabolic syndrome: A review of the literature. Vol. 120, Pharmacological Research. 2017. p. 34-42.

[15] Mokdad AH, Ford ES, Bowman BA, Dietz WH, Vinicor F, Bales VS, et al. Prevalence of obesity, diabetes, and obesity-related health risk factors, 2001. JAMA. 2003 Jan;289(1):76-9.

[16] Finucane MM, Stevens GA, Cowan MJ, Danaei G, Lin JK, Paciorek CJ, et al. National, regional, and global trends in body-mass index since 1980: Systematic analysis of health examination surveys and epidemiological studies with 960 country-years and $9 \cdot 1$ million participants. Lancet. 2011 Feb;377(9765):557-67.

[17] World Health Organization. Obesity and overweight. 2018. 
1 [18] Ford ES. Risks for all-cause mortality, cardiovascular disease, and diabetes associated with the metabolic syndrome: a summary of the evidence. Diabetes Care [Internet]. 2005 Jul;28(7):1769-78. Available from: http://www.ncbi.nlm.nih.gov/pubmed/15983333

[19] Ioannidis JPA. Implausible results in human nutrition research. BMJ. 2013 Nov;347:f6698.

[20] Burdge GC, Lillycrop KA, Jackson AA. Nutrition in early life, and risk of cancer and metabolic disease: Alternative endings in an epigenetic tale? Br J Nutr. 2009 Dec;101(5):619-30.

[21] Menendez-Castro C, Rascher W, Hartner A. Intrauterine growth restriction - impact on cardiovascular diseases later in life. Mol Cell Pediatr. 2018 Dec;5(1):4.

[22] Holmes M V, Dale CE, Zuccolo L, Silverwood RJ, Guo Y, Ye Z, et al. Association between alcohol and cardiovascular disease: Mendelian randomisation analysis based on individual participant data. BMJ. 2014 Jul;349:g4164.

[23] World Health Organization. Global status report on Alcohol and Health. 2014.

[24] Lim SS, Vos T, Flaxman AD, Danaei G, Shibuya K, Adair-Rohani H, et al. A comparative risk assessment of burden of disease and injury attributable to 67 risk factors and risk factor clusters in 21 regions, 1990-2010: a systematic analysis for the Global Burden of Disease Study 2010. Lancet. 2012 Dec;380(9859):2224-60.

[25] Sattelmair J, Pertman J, Ding EL, Kohl HW, III, Haskell W, et al. Dose-Response Between Physical Activity and Risk of Coronary Heart Disease: A Meta-Analysis. Circulation. 2011 Aug;124(7):789-95.

[26] Löllgen H, Böckenhoff A, Knapp G. Physical activity and all-cause mortality: An updated meta-analysis with different intensity categories. 2009 Mar p. 213-24.

[27] Fletcher GF, Balady G, Blair SN, Blumenthal J, Caspersen C, Chaitman B, et al. Statement on exercise: benefits and recommendations for physical activity programs for 
all Americans. A statement for health professionals by the Committee on Exercise and Cardiac Rehabilitation of the Council on Clinical Cardiology, American Heart Associ. Circulation. 1996 Aug;94(4):857-62.

[28] Gottlieb DJ, Redline S, Nieto FJ, Baldwin CM, Newman AB, Resnick HE, et al. Association of usual sleep duration with hypertension: the Sleep Heart Health Study. Sleep. 2006 Aug;29(8):1009-14.

[29] Wolk R, Somers VK. Sleep and the metabolic syndrome. Vol. 92, Experimental Physiology. 2007. p. 67-78.

[30] Brook RD, Rajagopalan S, Pope CA, Brook JR, Bhatnagar A, Diez-Roux A V., et al. Particulate Matter Air Pollution and Cardiovascular Disease: An update to the scientific statement from the American Heart Association. Circulation [Internet]. 2010 Jun;121(21):2331-78. Available from: https://www.ahajournals.org/doi/10.1161/CIR.0b013e3181dbece1

[31] Di Ciaula A, Portincasa P. Diet and contaminants: driving the rise to obesity epidemics? Curr Med Chem [Internet]. 2017 May 17;24. Available from: http://www.ncbi.nlm.nih.gov/pubmed/28521687

[32] Kontis V, Mathers CD, Rehm J, Stevens GA, Shield KD, Bonita R, et al. Contribution of six risk factors to achieving the $25 \times 25$ non-communicable disease mortality reduction target: a modelling study. Lancet. 2014 Aug;384(9941):427-37.

[33] Ormazabal V, Nair S, Elfeky O, Aguayo C, Salomon C, Zuñiga FA. Association between insulin resistance and the development of cardiovascular disease. Cardiovasc Diabetol [Internet]. 2018 Dec 31;17(1):122. Available from: http://www.ncbi.nlm.nih.gov/pubmed/30170598

[34] Bonora E, Kiechl S, Willeit J, Oberhollenzer F, Egger G, Targher G, et al. Prevalence of insulin resistance in metabolic disorders: the Bruneck Study. Diabetes [Internet]. 1998 
Oct;47(10):1643-9. Available from: http://www.ncbi.nlm.nih.gov/pubmed/9753305

[35] Howard G, O’Leary DH, Zaccaro D, Haffner S, Rewers M, Hamman R, et al. Insulin sensitivity and atherosclerosis. The Insulin Resistance Atherosclerosis Study (IRAS) Investigators. Circulation [Internet]. 1996 May 15;93(10):1809-17. Available from: http://www.ncbi.nlm.nih.gov/pubmed/8635260

[36] Tenenbaum A, Adler Y, Boyko V, Tenenbaum H, Fisman EZ, Tanne D, et al. Insulin resistance is associated with increased risk of major cardiovascular events in patients with preexisting coronary artery disease. Am Heart J [Internet]. 2007 Apr;153(4):559_ 65. Available from: http://www.ncbi.nlm.nih.gov/pubmed/17383294

[37] Gast KB, Tjeerdema N, Stijnen T, Smit JWA, Dekkers OM. Insulin resistance and risk of incident cardiovascular events in adults without diabetes: meta-analysis. PLoS One [Internet]. 2012;7(12):e52036. Available from: http://www.ncbi.nlm.nih.gov/pubmed/23300589

[38] Eddy D, Schlessinger L, Kahn R, Peskin B, Schiebinger R. Relationship of insulin resistance and related metabolic variables to coronary artery disease: a mathematical analysis. Diabetes Care [Internet]. 2009 Feb;32(2):361-6. Available from: http://www.ncbi.nlm.nih.gov/pubmed/19017770

[39] Reaven G. Insulin resistance and coronary heart disease in nondiabetic individuals. Arterioscler Thromb Vasc Biol [Internet]. 2012 Aug;32(8):1754-9. Available from: http://www.ncbi.nlm.nih.gov/pubmed/22815340

[40] Laakso M, Kuusisto J. Insulin resistance and hyperglycaemia in cardiovascular disease development. Nat Rev Endocrinol [Internet]. 2014 May;10(5):293-302. Available from: http://www.ncbi.nlm.nih.gov/pubmed/24663222

[41] Rader DJ. Effect of insulin resistance, dyslipidemia, and intra-abdominal adiposity on the development of cardiovascular disease and diabetes mellitus. Am J Med [Internet]. 
2007 Mar;120(3 Suppl 1):S12-8. Available from:

http://www.ncbi.nlm.nih.gov/pubmed/17320517

[42] Savaiano DA, Story JA. Cardiovascular disease and fiber: is insulin resistance the missing link? Nutr Rev [Internet]. 2000 Nov;58(11):356-8. Available from: http://www.ncbi.nlm.nih.gov/pubmed/11140908

[43] Kong C, Elatrozy T, Anyaoku V, Robinson S, Richmond W, Elkeles RS. Insulin resistance, cardiovascular risk factors and ultrasonically measured early arterial disease in normotensive Type 2 diabetic subjects. Diabetes Metab Res Rev [Internet]. 16(6):448-53. Available from: http://www.ncbi.nlm.nih.gov/pubmed/11114104

[44] Ginsberg HN. Insulin resistance and cardiovascular disease. J Clin Invest [Internet]. 2000 Aug;106(4):453-8. Available from: http://www.ncbi.nlm.nih.gov/pubmed/10953019

[45] Bloomgarden ZT. Insulin resistance, dyslipidemia, and cardiovascular disease. Diabetes Care [Internet]. $2007 \mathrm{Aug} ; 30(8): 2164-70$. Available from: http://www.ncbi.nlm.nih.gov/pubmed/17855278

[46] Kozakova M, Natali A, Dekker J, Beck-Nielsen H, Laakso M, Nilsson P, et al. Insulin sensitivity and carotid intima-media thickness: relationship between insulin sensitivity and cardiovascular risk study. Arterioscler Thromb Vasc Biol [Internet]. 2013 Jun;33(6):1409-17. Available from: http://www.ncbi.nlm.nih.gov/pubmed/23599442

[47] Bornfeldt KE, Tabas I. Insulin resistance, hyperglycemia, and atherosclerosis. Cell Metab [Internet]. 2011 Nov 2;14(5):575-85. Available from: http://www.ncbi.nlm.nih.gov/pubmed/22055501

[48] Davidson JA, Parkin CG. Is hyperglycemia a causal factor in cardiovascular disease? Does proving this relationship really matter? Yes. Diabetes Care [Internet]. 2009 Nov;32 Suppl 2:S331-3. Available from: http://www.ncbi.nlm.nih.gov/pubmed/19875575 
1 [49] Chanda D, Luiken JJFP, Glatz JFC. Signaling pathways involved in cardiac energy

2 metabolism. FEBS Lett [Internet]. 2016;590(15):2364-74. Available from: http://www.ncbi.nlm.nih.gov/pubmed/27403883

[50] Zhou YT, Grayburn P, Karim A, Shimabukuro M, Higa M, Baetens D, et al. Lipotoxic heart disease in obese rats: implications for human obesity. Proc Natl Acad Sci U S A [Internet]. 2000 Feb 15;97(4):1784-9. Available from: http://www.ncbi.nlm.nih.gov/pubmed/10677535

[51] Wu G, Meininger CJ. Nitric oxide and vascular insulin resistance. Biofactors [Internet]. 2009;35(1):21-7. Available from: http://www.ncbi.nlm.nih.gov/pubmed/19319842

[52] Wang CCL, Gurevich I, Draznin B. Insulin affects vascular smooth muscle cell phenotype and migration via distinct signaling pathways. Diabetes [Internet]. 2003 Oct;52(10):2562-9. Available from: http://www.ncbi.nlm.nih.gov/pubmed/14514641

[53] Dinesh Shah A, Langenberg C, Rapsomaniki E, Denaxas S, Pujades-Rodriguez M, Gale $\mathrm{CP}$, et al. Type 2 diabetes and incidence of a wide range of cardiovascular diseases: a cohort study in 1.9 million people. Lancet (London, England) [Internet]. $2015 \mathrm{Feb}$ 26;385 Suppl:S86. Available from: http://www.ncbi.nlm.nih.gov/pubmed/26312908

[54] Martín-Timón I, Sevillano-Collantes C, Segura-Galindo A, Del Cañizo-Gómez FJ. Type 2 diabetes and cardiovascular disease: Have all risk factors the same strength? World $\mathbf{J}$ Diabetes [Internet]. 2014 Aug 15;5(4):444-70. Available from: http://www.ncbi.nlm.nih.gov/pubmed/25126392

[55] Ciccone MM, Cortese F, Gesualdo M, Donvito I, Carbonara S, De Pergola G. A Glycemic Threshold of $90 \mathrm{mg} / \mathrm{dl}$ Promotes Early Signs of Atherosclerosis in Apparetly Healthy Overweight/Obese Subjects. Endocr Metab Immune Disord Drug Targets [Internet]. 2016;16(4):288-95. Available from: http://www.ncbi.nlm.nih.gov/pubmed/27919218 
[56] Meyer ML, Gotman NM, Soliman EZ, Whitsel EA, Arens R, Cai J, et al. Association of glucose homeostasis measures with heart rate variability among Hispanic/Latino adults without diabetes: the Hispanic Community Health Study/Study of Latinos (HCHS/SOL). Cardiovasc Diabetol [Internet]. 2016 Mar 16;15:45. Available from: http://www.ncbi.nlm.nih.gov/pubmed/26983644

[57] Paneni F, Volpe M, Lüscher TF, Cosentino F. SIRT1, p66(Shc), and Set7/9 in vascular hyperglycemic memory: bringing all the strands together. Diabetes [Internet]. 2013 Jun;62(6):1800-7. Available from: http://www.ncbi.nlm.nih.gov/pubmed/23704521

[58] Ceriello A. The emerging challenge in diabetes: the "metabolic memory". Vascul Pharmacol [Internet]. 2012;57(5-6):133-8. Available from: http://www.ncbi.nlm.nih.gov/pubmed/22609133

[59] Fiorentino TV, Prioletta A, Zuo P, Folli F. Hyperglycemia-induced oxidative stress and its role in diabetes mellitus related cardiovascular diseases. Curr Pharm Des [Internet]. 2013;19(32):5695-703. Available from: http://www.ncbi.nlm.nih.gov/pubmed/23448484

[60] Pistrosch F, Natali A, Hanefeld M. Is hyperglycemia a cardiovascular risk factor? Diabetes Care [Internet]. 2011 May;34 Suppl 2:S128-31. Available from: http://www.ncbi.nlm.nih.gov/pubmed/21525443

[61] Nowotny K, Jung T, Höhn A, Weber D, Grune T. Advanced glycation end products and oxidative stress in type 2 diabetes mellitus. Biomolecules [Internet]. 2015 Mar 16;5(1):194-222. Available from: http://www.ncbi.nlm.nih.gov/pubmed/25786107

[62] Yan SF, Ramasamy R, Schmidt AM. The RAGE axis: a fundamental mechanism signaling danger to the vulnerable vasculature. Circ Res [Internet]. 2010 Mar 19;106(5):842-53. Available from: http://www.ncbi.nlm.nih.gov/pubmed/20299674

[63] Goldberg IJ. Clinical review 124: Diabetic dyslipidemia: causes and consequences. J Clin Endocrinol Metab [Internet]. 2001 Mar;86(3):965-71. Available from: 
http://www.ncbi.nlm.nih.gov/pubmed/11238470

[64] Miller M. Dyslipidemia and cardiovascular risk: the importance of early prevention. QJM [Internet]. 2009 Sep;102(9):657-67. Available from: http://www.ncbi.nlm.nih.gov/pubmed/19498039

[65] Sparks JD, Sparks CE, Adeli K. Selective hepatic insulin resistance, VLDL overproduction, and hypertriglyceridemia. Arterioscler Thromb Vasc Biol [Internet]. 2012 Sep;32(9):2104-12. Available from: http://www.ncbi.nlm.nih.gov/pubmed/22796579

[66] Austin MA, Hokanson JE, Edwards KL. Hypertriglyceridemia as a cardiovascular risk factor. Am J Cardiol [Internet]. 1998 Feb 26;81(4A):7B-12B. Available from: http://www.ncbi.nlm.nih.gov/pubmed/9526807

[67] Hokanson JE. Hypertriglyceridemia and risk of coronary heart disease. Curr Cardiol Rep [Internet]. 2002 Nov;4(6):488-93. Available from: http://www.ncbi.nlm.nih.gov/pubmed/12379171

[68] Wende AR, Abel ED. Lipotoxicity in the heart. Biochim Biophys Acta [Internet]. 2010 Mar;1801(3):311-9. Available from: http://www.ncbi.nlm.nih.gov/pubmed/19818871

[69] Mei Y, Thompson MD, Cohen RA, Tong X. Endoplasmic Reticulum Stress and Related Pathological Processes. J Pharmacol Biomed Anal [Internet]. 2013 Nov 15;1(2):1000107. Available from: http://www.ncbi.nlm.nih.gov/pubmed/24611136

[70] Taddeo EP, Laker RC, Breen DS, Akhtar YN, Kenwood BM, Liao JA, et al. Opening of the mitochondrial permeability transition pore links mitochondrial dysfunction to insulin resistance in skeletal muscle. Mol Metab [Internet]. 2014 Apr;3(2):124-34. Available from: http://www.ncbi.nlm.nih.gov/pubmed/24634818

[71] Mandavia CH, Aroor AR, Demarco VG, Sowers JR. Molecular and metabolic mechanisms of cardiac dysfunction in diabetes. Life Sci [Internet]. 2013 Mar 
28;92(11):601-8. Available from: http://www.ncbi.nlm.nih.gov/pubmed/23147391

[72] Peña-Blanco A, García-Sáez AJ. Bax, Bak and beyond - mitochondrial performance in apoptosis. FEBS J [Internet]. 2018;285(3):416-31. Available from: http://www.ncbi.nlm.nih.gov/pubmed/28755482

[73] Bhola PD, Letai A. Mitochondria-Judges and Executioners of Cell Death Sentences. Mol Cell [Internet]. 2016 Mar 3;61(5):695-704. Available from: http://www.ncbi.nlm.nih.gov/pubmed/26942674

[74] Matilainen O, Quirós PM, Auwerx J. Mitochondria and Epigenetics - Crosstalk in Homeostasis and Stress. Trends Cell Biol [Internet]. 2017;27(6):453-63. Available from: http://www.ncbi.nlm.nih.gov/pubmed/28274652

[75] Cogliati S, Enriquez JA, Scorrano L. Mitochondrial Cristae: Where Beauty Meets Functionality. Trends Biochem Sci [Internet]. 2016 Mar;41(3):261-73. Available from: http://www.ncbi.nlm.nih.gov/pubmed/26857402

[76] Friedman JR, Nunnari J. Mitochondrial form and function. Nature [Internet]. 2014 Jan 16;505(7483):335-43. Available from: http://www.ncbi.nlm.nih.gov/pubmed/24429632

[77] Lee C, Zeng J, Drew BG, Sallam T, Martin-Montalvo A, Wan J, et al. The mitochondrial-derived peptide MOTS-c promotes metabolic homeostasis and reduces obesity and insulin resistance. Cell Metab [Internet]. 2015 Mar 3;21(3):443-54. Available from: http://www.ncbi.nlm.nih.gov/pubmed/25738459

[78] Lee C, Yen K, Cohen P. Humanin: a harbinger of mitochondrial-derived peptides? Trends Endocrinol Metab [Internet]. 2013 May;24(5):222-8. Available from: http://www.ncbi.nlm.nih.gov/pubmed/23402768

[79] Schorr S, van der Laan M. Integrative functions of the mitochondrial contact site and cristae organizing system. Semin Cell Dev Biol [Internet]. 2018;76:191-200. Available from: http://www.ncbi.nlm.nih.gov/pubmed/28923515 
1 [80] Stock D, Leslie AG, Walker JE. Molecular architecture of the rotary motor in ATP synthase. Science [Internet]. 1999 Nov 26;286(5445):1700-5. Available from: http://www.ncbi.nlm.nih.gov/pubmed/10576729

[81] Kim HD, Kim CH, Rah BJ, Chung HI, Shim TS. Quantitative study on the relation between structural and functional properties of the hearts from three different mammals. Anat Rec [Internet]. 1994 Feb;238(2):199-206. Available from: http://www.ncbi.nlm.nih.gov/pubmed/8154606

[82] Barth E, Stämmler G, Speiser B, Schaper J. Ultrastructural quantitation of mitochondria and myofilaments in cardiac muscle from 10 different animal species including man. $\mathbf{J}$ Mol Cell Cardiol [Internet]. 1992 Jul;24(7):669-81. Available from: http://www.ncbi.nlm.nih.gov/pubmed/1404407

[83] Balaban RS. Cardiac energy metabolism homeostasis: role of cytosolic calcium. J Mol Cell Cardiol [Internet]. 2002 Oct;34(10):1259-71. Available from: http://www.ncbi.nlm.nih.gov/pubmed/12392982

[84] Harris DA, Das AM. Control of mitochondrial ATP synthesis in the heart. Biochem J [Internet]. 1991 Dec 15;280 ( Pt 3:561-73. Available from: http://www.ncbi.nlm.nih.gov/pubmed/1837214

[85] Kolwicz SC, Purohit S, Tian R. Cardiac metabolism and its interactions with contraction, growth, and survival of cardiomyocytes. Circ Res [Internet]. 2013 Aug 16;113(5):60316. Available from: http://www.ncbi.nlm.nih.gov/pubmed/23948585

[86] Stanley WC, Recchia FA, Lopaschuk GD. Myocardial substrate metabolism in the normal and failing heart. Physiol Rev [Internet]. 2005 Jul;85(3):1093-129. Available from: http://www.ncbi.nlm.nih.gov/pubmed/15987803

[87] Wentz AE, D'Avignon DA, Weber ML, Cotter DG, Doherty JM, Kerns R, et al. Adaptation of myocardial substrate metabolism to a ketogenic nutrient environment. J 
Biol Chem [Internet]. 2010 Aug 6;285(32):24447-56. Available from: http://www.ncbi.nlm.nih.gov/pubmed/20529848

[88] Walklate J, Ujfalusi Z, Geeves MA. Myosin isoforms and the mechanochemical crossbridge cycle. J Exp Biol [Internet]. 2016 Jan;219(Pt 2):168-74. Available from: http://www.ncbi.nlm.nih.gov/pubmed/26792327

[89] Balaban RS. The role of $\mathrm{Ca}(2+)$ signaling in the coordination of mitochondrial ATP production with cardiac work. Biochim Biophys Acta [Internet]. 2009 Nov;1787(11):1334-41. Available from: http://www.ncbi.nlm.nih.gov/pubmed/19481532

[90] De Stefani D, Raffaello A, Teardo E, Szabò I, Rizzuto R. A forty-kilodalton protein of the inner membrane is the mitochondrial calcium uniporter. Nature [Internet]. 2011;476(7360):336-40. Available from: http://www.ncbi.nlm.nih.gov/pubmed/21685888

[91] Hajnóczky G, Robb-Gaspers LD, Seitz MB, Thomas AP. Decoding of cytosolic calcium oscillations in the mitochondria. Cell [Internet]. 1995 Aug 11;82(3):415-24. Available from: http://www.ncbi.nlm.nih.gov/pubmed/7634331

[92] Rizzuto R, Pinton P, Carrington W, Fay FS, Fogarty KE, Lifshitz LM, et al. Close contacts with the endoplasmic reticulum as determinants of mitochondrial $\mathrm{Ca} 2+$ responses. Science [Internet]. 1998 Jun 12;280(5370):1763-6. Available from: http://www.ncbi.nlm.nih.gov/pubmed/9624056

[93] Giorgi C, Marchi S, Pinton P. The machineries, regulation and cellular functions of mitochondrial calcium. Nat Rev Mol Cell Biol [Internet]. 2018 Nov;19(11):713-30. Available from: http://www.ncbi.nlm.nih.gov/pubmed/30143745

[94] Palty R, Silverman WF, Hershfinkel M, Caporale T, Sensi SL, Parnis J, et al. NCLX is an essential component of mitochondrial $\mathrm{Na}+/ \mathrm{Ca} 2+$ exchange. Proc Natl Acad Sci U S A 
[Internet]. 2010 Jan 5;107(1):436-41. Available from:

http://www.ncbi.nlm.nih.gov/pubmed/20018762

[95] Brown DA, Perry JB, Allen ME, Sabbah HN, Stauffer BL, Shaikh SR, et al. Expert consensus document: Mitochondrial function as a therapeutic target in heart failure. Nat Rev Cardiol [Internet]. 2017;14(4):238-50. Available from: http://www.ncbi.nlm.nih.gov/pubmed/28004807

[96] Abel ED. Obesity stresses cardiac mitochondria even when you are young. J Am Coll Cardiol [Internet]. 2011 Feb 1;57(5):586-9. Available from: http://www.ncbi.nlm.nih.gov/pubmed/21272750

[97] Niemann B, Chen Y, Teschner M, Li L, Silber R-E, Rohrbach S. Obesity induces signs of premature cardiac aging in younger patients: the role of mitochondria. J Am Coll Cardiol [Internet]. 2011 Feb 1;57(5):577-85. Available from: http://www.ncbi.nlm.nih.gov/pubmed/21272749

[98] Stacchiotti A, Favero G, Giugno L, Golic I, Korac A, Rezzani R. Melatonin Efficacy in Obese Leptin-Deficient Mice Heart. Nutrients [Internet]. 2017 Dec 5;9(12):E1323. Available from: http://www.ncbi.nlm.nih.gov/pubmed/29206172

[99] Gottlieb RA, Thomas A. Mitophagy and Mitochondrial Quality Control Mechanisms in the Heart. Curr Pathobiol Rep [Internet]. 2017 Jun;5(2):161-9. Available from: http://www.ncbi.nlm.nih.gov/pubmed/29082112

[100] Zeng H, Vaka VR, He X, Booz GW, Chen J-X. High-fat diet induces cardiac remodelling and dysfunction: assessment of the role played by SIRT3 loss. J Cell Mol Med [Internet]. 2015 Aug;19(8):1847-56. Available from: http://www.ncbi.nlm.nih.gov/pubmed/25782072

[101] Kendrick AA, Choudhury M, Rahman SM, McCurdy CE, Friederich M, Van Hove JLK, et al. Fatty liver is associated with reduced SIRT3 activity and mitochondrial protein 
hyperacetylation. Biochem J [Internet]. 2011 Feb 1;433(3):505-14. Available from: http://www.ncbi.nlm.nih.gov/pubmed/21044047

[102] de Moura Freitas C, Nascimento LCP do, Braz GRF, Andrade-Silva SC, Lima-Junior NC, de Araujo Silva T, et al. Mitochondrial impairment following neonatal overfeeding: A comparison between normal and ischemic-reperfused hearts. J Cell Biochem [Internet]. 2018 Oct 28; Available from: http://www.ncbi.nlm.nih.gov/pubmed/30368910

[103] Ferey JLA, Boudoures AL, Reid M, Drury A, Scheaffer S, Modi Z, et al. A maternal high-fat, high-sucrose diet induces transgenerational cardiac mitochondrial dysfunction independently of maternal mitochondrial inheritance. Am J Physiol Heart Circ Physiol [Internet]. 2019 May 1;316(5):H1202-10. Available from: http://www.ncbi.nlm.nih.gov/pubmed/30901280

[104] López-otín C, Blasco MA, Partridge L, Serrano M, Kroemer G. The Hallmarks of Aging. Cell. 2013;153(6):1194-217.

[105] Bratic A, Larsson N. The role of mitochondria in aging. J Clin Invest. 2013;123(3):9517.

[106] Gonzalez-Freire M, De Cabo R, Bernier M, Sollott SJ, Fabbri E, Navas P, et al. Reconsidering the Role of Mitochondria in Aging. Journals Gerontol - Ser A Biol Sci Med Sci. 2015;70(11):1334-42.

[107] Lane RK, Hilsabeck T, Rea SL. The role of mitochondrial dysfunction in age-related diseases. Biochim Biophys Acta [Internet]. 2015 Nov;1847(11):1387-400. Available from: http://www.ncbi.nlm.nih.gov/pubmed/26050974

[108] Payne BAI, Chinnery PF. Mitochondrial dysfunction in aging: Much progress but many unresolved questions. Biochim Biophys Acta - Bioenerg [Internet]. 2015;1847(11):1347-53. Available from: http://dx.doi.org/10.1016/j.bbabio.2015.05.022

[109] HARMAN D. Aging: a theory based on free radical and radiation chemistry. J Gerontol 
[Internet]. $1956 \mathrm{Jul} ; 11(3): 298-300$. Available from:

http://www.ncbi.nlm.nih.gov/pubmed/13332224

[110] Balaban RS, Nemoto S, Finkel T. Mitochondria, oxidants, and aging. Cell. 2005;120(4):483-95.

[111] Parodi-Rullán RM, Chapa-Dubocq XR, Javadov S. Acetylation of Mitochondrial Proteins in the Heart: The Role of SIRT3. Front Physiol [Internet]. 2018;9:1094. Available from: http://www.ncbi.nlm.nih.gov/pubmed/30131726

[112] Matsushima S, Sadoshima J. The role of sirtuins in cardiac disease. Am J Physiol Heart Circ Physiol [Internet]. 2015 Nov;309(9):H1375-89. Available from: http://www.ncbi.nlm.nih.gov/pubmed/26232232

[113] Sadoshima J. Sirt3 targets mPTP and prevents aging in the heart. Aging (Albany NY). 2011;3(1):12-3.

[114] He X, Zeng H, Chen J-X. Ablation of SIRT3 causes coronary microvascular dysfunction and impairs cardiac recovery post myocardial ischemia. Int J Cardiol [Internet]. $2016 \mathrm{Jul}$ 15;215:349-57. Available from: http://www.ncbi.nlm.nih.gov/pubmed/27128560

[115] Cosentino F, Francia P, Camici GG, Pelicci PG, Volpe M, Lüscher TF. Final Common Molecular Pathways of Aging and Cardiovascular Disease: Role of the p66Shc protein. Arterioscler Thromb Vasc Biol. 2007;28(4):622-8.

[116] Camici GG, Savarese G, Akhmedov A, Lüscher TF. Molecular mechanism of endothelial and vascular aging: Implications for cardiovascular disease. Eur Heart J. 2015;36(48):3392-403.

[117] Migliaccio E, Giogio M, Mele S, Pelicci G, Reboldi P, Pandolfi PP, et al. The p66(shc) adaptor protein controls oxidative stress response and life span in mammals. Nature. 1999;402(6759):309-13.

[118] Shi Y, Savarese G, Perrone-Filardi P, Lüscher TF, Camici GG. Enhanced age-dependent 
cerebrovascular dysfunction is mediated by adaptor protein p66 Shc. Int J Cardiol [Internet]. 2014;175(3):446-50. Available from: http://dx.doi.org/10.1016/j.ijcard.2014.06.025

[119] Spescha RD, Glanzmann M, Simic B, Witassek F, Keller S, Akhmedov A, et al. Adaptor protein p66Shc mediates hypertension-associated, cyclic stretch-dependent, endothelial damage. Hypertension. 2014;64(2):347-53.

[120] Spescha RD, Shi Y, Wegener S, Keller S, Weber B, Wyss MM, et al. Deletion of the ageing gene p66Shc reduces early stroke size following ischaemia/reperfusion brain injury. Eur Heart J. 2013;34(2):96-103.

[121] Lee W-H, Higuchi H, Ikeda S, Macke EL, Takimoto T, Pattnaik BR, et al. Mouse Tmem135 mutation reveals a mechanism involving mitochondrial dynamics that leads to age-dependent retinal pathologies. Elife [Internet]. 2016;5:e19264. Available from: http://www.ncbi.nlm.nih.gov/pubmed/27863209

[122] Song M, Mihara K, Chen Y, Scorrano L, Dorn GW. Mitochondrial fission and fusion factors reciprocally orchestrate mitophagic culling in mouse hearts and cultured fibroblasts. Cell Metab [Internet]. 2015 Feb 3;21(2):273-86. Available from: http://www.ncbi.nlm.nih.gov/pubmed/25600785

[123] Lewis SA, Takimoto T, Mehrvar S, Higuchi H, Doebley A-L, Stokes G, et al. The effect of Tmem135 overexpression on the mouse heart. PLoS One [Internet]. 2018;13(8):e0201986. Available from: http://www.ncbi.nlm.nih.gov/pubmed/30102730

[124] Corral-Debrinski M, Shoffner JM, Lott MT, Wallace DC. Association of mitochondrial DNA damage with aging and coronary atherosclerotic heart disease. Mutat Res [Internet]. 1992 Sep;275(3-6):169-80. Available from: http://www.ncbi.nlm.nih.gov/pubmed/1383759

[125] Li YY, Hengstenberg C, Maisch B. Whole mitochondrial genome amplification reveals 
basal level multiple deletions in mtDNA of patients with dilated cardiomyopathy.

Biochem Biophys Res Commun [Internet]. 1995 May 5;210(1):211-8. Available from: http://www.ncbi.nlm.nih.gov/pubmed/7741744

[126] Dai D-F, Chen T, Wanagat J, Laflamme M, Marcinek DJ, Emond MJ, et al. Agedependent cardiomyopathy in mitochondrial mutator mice is attenuated by overexpression of catalase targeted to mitochondria. Aging Cell [Internet]. 2010 Aug;9(4):536-44. Available from: http://www.ncbi.nlm.nih.gov/pubmed/20456298

[127] Matthews PM, Hopkin J, Brown RM, Stephenson JB, Hilton-Jones D, Brown GK. Comparison of the relative levels of the $3243(\mathrm{~A}-->\mathrm{G})$ mtDNA mutation in heteroplasmic adult and fetal tissues. J Med Genet [Internet]. 1994 Jan;31(1):41-4. Available from: http://www.ncbi.nlm.nih.gov/pubmed/8151636

[128] Tranah GJ, Katzman SM, Lauterjung K, Yaffe K, Manini TM, Kritchevsky S, et al. Mitochondrial DNA m.3243A > G heteroplasmy affects multiple aging phenotypes and risk of mortality. Sci Rep [Internet]. 2018 Aug 8;8(1):11887. Available from: http://www.ncbi.nlm.nih.gov/pubmed/30089816

[129] Bugger H, Abel ED. Mitochondria in the diabetic heart. Cardiovasc Res [Internet]. 2010 Nov 1;88(2):229-40. Available from: http://www.ncbi.nlm.nih.gov/pubmed/20639213

[130] Duncan JG. Mitochondrial dysfunction in diabetic cardiomyopathy. Biochim Biophys Acta [Internet]. 2011 Jul;1813(7):1351-9. Available from: http://www.ncbi.nlm.nih.gov/pubmed/21256163

[131] Mazumder PK, O’Neill BT, Roberts MW, Buchanan J, Yun UJ, Cooksey RC, et al. Impaired cardiac efficiency and increased fatty acid oxidation in insulin-resistant ob/ob mouse hearts. Diabetes [Internet]. 2004 Sep;53(9):2366-74. Available from: http://www.ncbi.nlm.nih.gov/pubmed/15331547

[132] Buchanan J, Mazumder PK, Hu P, Chakrabarti G, Roberts MW, Yun UJ, et al. Reduced 
cardiac efficiency and altered substrate metabolism precedes the onset of hyperglycemia and contractile dysfunction in two mouse models of insulin resistance and obesity. Endocrinology [Internet]. 2005 Dec;146(12):5341-9. Available from: http://www.ncbi.nlm.nih.gov/pubmed/16141388

[133] Rasool S, Geetha T, Broderick TL, Babu JR. High Fat With High Sucrose Diet Leads to Obesity and Induces Myodegeneration. Front Physiol [Internet]. 2018;9:1054. Available from: http://www.ncbi.nlm.nih.gov/pubmed/30258366

[134] Vadvalkar SS, Matsuzaki S, Eyster CA, Giorgione JR, Bockus LB, Kinter CS, et al. Decreased Mitochondrial Pyruvate Transport Activity in the Diabetic Heart: ROLE OF MITOCHONDRIAL PYRUVATE CARRIER 2 (MPC2) ACETYLATION. J Biol Chem [Internet]. 2017;292(11):4423-33. Available from: http://www.ncbi.nlm.nih.gov/pubmed/28154187

[135] Koentges C, Pfeil K, Schnick T, Wiese S, Dahlbock R, Cimolai MC, et al. SIRT3 deficiency impairs mitochondrial and contractile function in the heart. Basic Res Cardiol [Internet]. 2015;110(4):36. Available from: http://www.ncbi.nlm.nih.gov/pubmed/25962702

[136] Gui J, Potthast A, Rohrbach A, Borns K, Das AM, von Versen-Höynck F. Gestational diabetes induces alterations of sirtuins in fetal endothelial cells. Pediatr Res [Internet]. 2016;79(5):788-98. Available from: http://www.ncbi.nlm.nih.gov/pubmed/26717002

[137] Camici GG, Schiavoni M, Francia P, Bachschmid M, Martin-Padura I, Hersberger M, et al. Genetic deletion of p66Shc adaptor protein prevents hyperglycemia-induced endothelial dysfunction and oxidative stress. Proc Natl Acad Sci. 2007;104(12):5217-22.

[138] Pagnin E, Fadini G, de Toni R, Tiengo A, Calò L, Avogaro A. Diabetes induces p66shc gene expression in human peripheral blood mononuclear cells: relationship to oxidative stress. J Clin Endocrinol Metab. 2005;90(2):1130-6. 
[139] Li W, Yao M, Wang R, Shi Y, Hou L, Hou Z, et al. Profile of cardiac lipid metabolism in STZ-induced diabetic mice. Lipids Health Dis [Internet]. 2018 Oct 9;17(1):231. Available from: http://www.ncbi.nlm.nih.gov/pubmed/30301464

[140] Edwards KS, Ashraf S, Lomax TM, Wiseman JM, Hall ME, Gava FN, et al. Uncoupling protein 3 deficiency impairs myocardial fatty acid oxidation and contractile recovery following ischemia/reperfusion. Basic Res Cardiol [Internet]. 2018;113(6):47. Available from: http://www.ncbi.nlm.nih.gov/pubmed/30374710

[141] Riojas-Hernández A, Bernal-Ramírez J, Rodríguez-Mier D, Morales-Marroquín FE, Domínguez-Barragán EM, Borja-Villa C, et al. Enhanced oxidative stress sensitizes the mitochondrial permeability transition pore to opening in heart from Zucker Fa/fa rats with type 2 diabetes. Life Sci [Internet]. 2015 Nov 15;141:32-43. Available from: http://www.ncbi.nlm.nih.gov/pubmed/26407476

[142] Sloan RC, Moukdar F, Frasier CR, Patel HD, Bostian PA, Lust RM, et al. Mitochondrial permeability transition in the diabetic heart: contributions of thiol redox state and mitochondrial calcium to augmented reperfusion injury. J Mol Cell Cardiol [Internet]. 2012 May;52(5):1009-18. Available from: http://www.ncbi.nlm.nih.gov/pubmed/22406429

[143] Lumini-Oliveira J, Magalhães J, Pereira C V, Moreira AC, Oliveira PJ, Ascensão A. Endurance training reverts heart mitochondrial dysfunction, permeability transition and apoptotic signaling in long-term severe hyperglycemia. Mitochondrion [Internet]. 2011 Jan;11(1):54-63. Available from: http://www.ncbi.nlm.nih.gov/pubmed/20654738

[144] Bertero E, Maack C. Calcium Signaling and Reactive Oxygen Species in Mitochondria. Circ Res [Internet]. 2018 May 11;122(10):1460-78. Available from: http://www.ncbi.nlm.nih.gov/pubmed/29748369

[145] Epstein PN, Overbeek PA, Means AR. Calmodulin-induced early-onset diabetes in transgenic mice. Cell. 1989;58(6):1067-73. 
1 [146] Epstein PN, Ribar TJ, Decker GL, Yaney G, Means AR. Elevated beta-cell calmodulin produces a unique insulin secretory defect in transgenic mice. Endocrinology [Internet]. 1992 Mar;130(3):1387-93. Available from: https://academic.oup.com/endo/articlelookup/doi/10.1210/endo.130.3.1371447

[147] Yu W, Niwa T, Miura Y, Horio F, Teradaira S, Ribar TJ, et al. Calmodulin overexpression causes $\mathrm{Ca}(2+)$-dependent apoptosis of pancreatic beta cells, which can be prevented by inhibition of nitric oxide synthase. Lab Invest. 2002 Sep;82(9):1229-39.

[148] Koves TR, Ussher JR, Noland RC, Slentz D, Mosedale M, Ilkayeva O, et al. Mitochondrial Overload and Incomplete Fatty Acid Oxidation Contribute to Skeletal Muscle Insulin Resistance. Cell Metab. 2008 Jan;7(1):45-56.

[149] Zhang L, Keung W, Samokhvalov V, Wang W, Lopaschuk GD. Role of fatty acid uptake and fatty acid $\beta$-oxidation in mediating insulin resistance in heart and skeletal muscle. Biochim Biophys Acta - Mol Cell Biol Lipids. 2010 Jan;1801(1):1-22.

[150] Bugger H, Boudina S, Hu XX, Tuinei J, Zaha VG, Theobald HA, et al. Type 1 Diabetic Akita Mouse Hearts Are Insulin Sensitive but Manifest Structurally Abnormal Mitochondria That Remain Coupled Despite Increased Uncoupling Protein 3. Diabetes [Internet]. 2008 Nov 1;57(11):2924-32. Available from: http://diabetes.diabetesjournals.org/cgi/doi/10.2337/db08-0079

[151] Bugger H, Chen D, Riehle C, Soto J, Theobald HA, Hu XX, et al. Tissue-Specific Remodeling of the Mitochondrial Proteome in Type 1 Diabetic Akita Mice. Diabetes. 2009 Sep;58(9):1986-97.

[152] Yoshioka M, Kayo T, Ikeda T, Koizuni A. A Novel Locus, Mody4, Distal to D7Mit189 on Chromosome 7 Determines Early-Onset NIDDM in Nonobese C57BL/6 (Akita) Mutant Mice. Diabetes [Internet]. 1997 May 1;46(5):887-94. Available from: http://diabetes.diabetesjournals.org/cgi/doi/10.2337/diab.46.5.887 
1 [153] Wang J, Takeuchi T, Tanaka S, Kubo S-K, Kayo T, Lu D, et al. A mutation in the insulin 2 gene induces diabetes with severe pancreatic $\beta$-cell dysfunction in the Mody mouse. $\mathbf{J}$ Clin Invest. 1999 Jan;103(1):27-37.

[154] Basu R, Oudit GY, Wang X, Zhang L, Ussher JR, Lopaschuk GD, et al. Type 1 diabetic cardiomyopathy in the Akita ( Ins2 WT/C96Y) mouse model is characterized by lipotoxicity and diastolic dysfunction with preserved systolic function. Am J Physiol Circ Physiol. 2009 Dec;297(6):H2096-108.

[155] Pulinilkunnil T, Kienesberger PC, Nagendran J, Waller TJ, Young ME, Kershaw EE, et al. Myocardial Adipose Triglyceride Lipase Overexpression Protects Diabetic Mice From the Development of Lipotoxic Cardiomyopathy. Diabetes. 2013 May;62(5):146477.

[156] Schaffner F, Thaler H. Nonalcoholic fatty liver disease. Prog Liver Dis [Internet]. 1986;8:283-98. Available from: http://www.ncbi.nlm.nih.gov/pubmed/3086934

[157] Smith BW, Adams LA. Non-alcoholic fatty liver disease. Crit Rev Clin Lab Sci [Internet]. 48(3):97-113. Available from: http://www.ncbi.nlm.nih.gov/pubmed/21875310

[158] Fotbolcu H, Zorlu E. Nonalcoholic fatty liver disease as a multi-systemic disease. World J Gastroenterol [Internet]. 2016 Apr 28;22(16):4079-90. Available from: http://www.ncbi.nlm.nih.gov/pubmed/27122660

[159] Targher G, Day CP, Bonora E. Risk of cardiovascular disease in patients with nonalcoholic fatty liver disease. N Engl J Med [Internet]. 2010 Sep 30;363(14):1341-50. Available from: http://www.ncbi.nlm.nih.gov/pubmed/20879883

[160] Adams LA, Anstee QM, Tilg H, Targher G. Non-alcoholic fatty liver disease and its relationship with cardiovascular disease and other extrahepatic diseases. Gut [Internet]. 2017;66(6):1138-53. Available from: http://www.ncbi.nlm.nih.gov/pubmed/28314735 
1 [161] Targher G, Byrne CD, Lonardo A, Zoppini G, Barbui C. Non-alcoholic fatty liver disease and risk of incident cardiovascular disease: A meta-analysis. J Hepatol [Internet]. 2016;65(3):589-600. Available from: http://www.ncbi.nlm.nih.gov/pubmed/27212244

[162] Nakajima T, Fujioka S, Tokunaga K, Matsuzawa Y, Tarui S. Correlation of intraabdominal fat accumulation and left ventricular performance in obesity. Am J Cardiol [Internet]. 1989 Aug 1;64(5):369-73. Available from: http://www.ncbi.nlm.nih.gov/pubmed/2756882

[163] Degli Esposti D, Hamelin J, Bosselut N, Saffroy R, Sebagh M, Pommier A, et al. Mitochondrial roles and cytoprotection in chronic liver injury. Biochem Res Int [Internet]. 2012;2012:387626. Available from: http://www.ncbi.nlm.nih.gov/pubmed/22745910

[164] Simões ICM, Fontes A, Pinton P, Zischka H, Wieckowski MR. Mitochondria in nonalcoholic fatty liver disease. Int J Biochem Cell Biol [Internet]. 2018;95:93-9. Available from: http://www.ncbi.nlm.nih.gov/pubmed/29288054

[165] Grattagliano I, Montezinho LP, Oliveira PJ, Frühbeck G, Gómez-Ambrosi J, Montecucco F, et al. Targeting mitochondria to oppose the progression of nonalcoholic fatty liver disease. Biochem Pharmacol [Internet]. 2019;160(September 2018):34-45. Available from: https://doi.org/10.1016/j.bcp.2018.11.020

[166] Begriche K, Igoudjil A, Pessayre D, Fromenty B. Mitochondrial dysfunction in NASH: Causes, consequences and possible means to prevent it. Mitochondrion. 2006;6(1):1-28.

[167] Satapati S, Kucejova B, Duarte JAG, Fletcher JA, Reynolds L, Sunny NE, et al. Mitochondrial metabolism mediates oxidative stress and inflammation in fatty liver. $\mathrm{J}$ Clin Invest [Internet]. 2015 Dec;125(12):4447-62. Available from: http://www.ncbi.nlm.nih.gov/pubmed/26571396

[168] Chess DJ, Stanley WC. Role of diet and fuel overabundance in the development and 
progression of heart failure. Cardiovasc Res [Internet]. 2008 Jul 15;79(2):269-78. Available from: http://www.ncbi.nlm.nih.gov/pubmed/18343896

[169] Kim BJ, Kim HS, Kang JG, Kim BS, Kang JH. Association of epicardial fat volume and nonalcoholic fatty liver disease with metabolic syndrome: From the CAESAR study. J Clin Lipidol [Internet]. 2016;10(6):1423-1430.e1. Available from: http://www.ncbi.nlm.nih.gov/pubmed/27919360

[170] Meng X, Wang W, Zhang K, Qi Y, An S, Wang S, et al. Epicardial adipose tissue volume is associated with non-alcoholic fatty liver disease and cardiovascular risk factors in the general population. Ther Clin Risk Manag [Internet]. 2018;14:1499-506. Available from: http://www.ncbi.nlm.nih.gov/pubmed/30197519

[171] Nie H, Pan Y, Zhou Y. Exosomal microRNA-194 causes cardiac injury and mitochondrial dysfunction in obese mice. Biochem Biophys Res Commun [Internet]. 2018;503(4):3174-9. Available from: http://www.ncbi.nlm.nih.gov/pubmed/30170731

[172] Chen D, Li X, Zhang L, Zhu M, Gao L. A high-fat diet impairs mitochondrial biogenesis, mitochondrial dynamics, and the respiratory chain complex in rat myocardial tissues. J Cell Biochem [Internet]. 2018 Nov;119(11):9602. Available from: http://www.ncbi.nlm.nih.gov/pubmed/30171706

[173] Marín-Royo G, Ortega-Hernández A, Martínez-Martínez E, Jurado-López R, Luaces M, Islas F, et al. The Impact of Cardiac Lipotoxicity on Cardiac Function and Mirnas Signature in Obese and Non-Obese Rats with Myocardial Infarction. Sci Rep [Internet]. 2019 Jan 24;9(1):444. Available from: http://www.ncbi.nlm.nih.gov/pubmed/30679580

[174] Peterson LR, Xanthakis V, Duncan MS, Gross S, Friedrich N, Völzke H, et al. Ceramide Remodeling and Risk of Cardiovascular Events and Mortality. J Am Heart Assoc [Internet]. 2018 May 3;7(10). Available from: http://www.ncbi.nlm.nih.gov/pubmed/29728014 
1 [175] Murray AJ, Cole MA, Lygate CA, Carr CA, Stuckey DJ, Little SE, et al. Increased mitochondrial uncoupling proteins, respiratory uncoupling and decreased efficiency in the chronically infarcted rat heart. J Mol Cell Cardiol [Internet]. 2008 Apr;44(4):694700. Available from: http://www.ncbi.nlm.nih.gov/pubmed/18328500

[176] Laskowski KR, Russell RR. Uncoupling proteins in heart failure. Curr Heart Fail Rep [Internet]. 2008 Jun;5(2):75-9. Available from: http://www.ncbi.nlm.nih.gov/pubmed/18765077

[177] Jin X, Xiang Z, Chen Y, Ma K, Ye Y, Li Y. Uncoupling protein and nonalcoholic fatty liver disease. Chin Med J (Engl) [Internet]. 2013 Aug;126(16):3151-5. Available from: http://www.ncbi.nlm.nih.gov/pubmed/23981628

[178] Baffy G, Zhang C-Y, Glickman JN, Lowell BB. Obesity-related fatty liver is unchanged in mice deficient for mitochondrial uncoupling protein 2. Hepatology [Internet]. 2002 Apr;35(4):753-61. Available from: http://www.ncbi.nlm.nih.gov/pubmed/11915020

[179] Al-Khader AA. The cardio-renal syndrome. Nephron [Internet]. 1988;48(1):86. Available from: http://www.ncbi.nlm.nih.gov/pubmed/3340265

[180] Ronco C, McCullough P, Anker SD, Anand I, Aspromonte N, Bagshaw SM, et al. Cardio-renal syndromes: report from the consensus conference of the acute dialysis quality initiative. Eur Heart J [Internet]. 2010 Mar;31(6):703-11. Available from: http://www.ncbi.nlm.nih.gov/pubmed/20037146

[181] McCullough PA, Ahmad A. Cardiorenal syndromes. World J Cardiol [Internet]. 2011 Jan 26;3(1):1-9. Available from: http://www.ncbi.nlm.nih.gov/pubmed/21286212

[182] Di Lullo L, Bellasi A, Barbera V, Russo D, Russo L, Di Iorio B, et al. Pathophysiology of the cardio-renal syndromes types 1-5: An uptodate. Indian Heart J [Internet]. 2017;69(2):255-65. Available from: http://www.ncbi.nlm.nih.gov/pubmed/28460776

[183] Bigelman E, Cohen L, Aharon-Hananel G, Levy R, Rozenbaum Z, Saada A, et al. 
Pathological presentation of cardiac mitochondria in a rat model for chronic kidney disease. PLoS One [Internet]. 2018;13(6):e0198196. Available from: http://www.ncbi.nlm.nih.gov/pubmed/29889834

[184] Eirin A, Ebrahimi B, Kwon SH, Fiala JA, Williams BJ, Woollard JR, et al. Restoration of Mitochondrial Cardiolipin Attenuates Cardiac Damage in Swine Renovascular Hypertension. J Am Heart Assoc [Internet]. 2016;5(6):e003118. Available from: http://www.ncbi.nlm.nih.gov/pubmed/27247333

[185] Dudek J, Hartmann M, Rehling P. The role of mitochondrial cardiolipin in heart function and its implication in cardiac disease. Biochim Biophys acta Mol basis Dis [Internet]. 2019 Apr 1;1865(4):810-21. Available from: http://www.ncbi.nlm.nih.gov/pubmed/30837070

[186] Sumida M, Doi K, Ogasawara E, Yamashita T, Hamasaki Y, Kariya T, et al. Regulation of Mitochondrial Dynamics by Dynamin-Related Protein-1 in Acute Cardiorenal Syndrome. J Am Soc Nephrol JASN [Internet]. 2015 Oct;26(10):2378-87. Available from: http://www.ncbi.nlm.nih.gov/pubmed/25644112

[187] Moore SC, Patel A V, Matthews CE, Berrington de Gonzalez A, Park Y, Katki HA, et al. Leisure time physical activity of moderate to vigorous intensity and mortality: a large pooled cohort analysis. PLoS Med [Internet]. 2012;9(11):e1001335. Available from: http://www.ncbi.nlm.nih.gov/pubmed/23139642

[188] Bhella PS, Hastings JL, Fujimoto N, Shibata S, Carrick-Ranson G, Palmer MD, et al. Impact of lifelong exercise "dose" on left ventricular compliance and distensibility. J Am Coll Cardiol [Internet]. 2014 Sep 23;64(12):1257-66. Available from: http://www.ncbi.nlm.nih.gov/pubmed/25236519

[189] Carson V, Ridgers ND, Howard BJ, Winkler EAH, Healy GN, Owen N, et al. Lightintensity physical activity and cardiometabolic biomarkers in US adolescents. PLoS One [Internet]. 2013;8(8):e71417. Available from: 
http://www.ncbi.nlm.nih.gov/pubmed/23951157

[190] WHO. Global recommendations on physical activity for health [Internet]. 2010. 58 p. Available from: https://www.who.int/ncds/prevention/physical-activity/guidelinesglobal-recommendations-for-health/en/

[191] WHO. Guidelines on physical activity, sedentary behaviour and sleep for children under 5 years of age [Internet]. 2019. 33 p. Available from: https://apps.who.int/iris/handle/10665/311664

[192] Lee D-C, Pate RR, Lavie CJ, Sui X, Church TS, Blair SN. Leisure-time running reduces all-cause and cardiovascular mortality risk. J Am Coll Cardiol [Internet]. 2014 Aug 5;64(5):472-81. Available from: http://www.ncbi.nlm.nih.gov/pubmed/25082581

[193] Kohl HW, Craig CL, Lambert EV, Inoue S, Alkandari JR, Leetongin G, et al. The pandemic of physical inactivity: global action for public health. Lancet (London, England) [Internet]. 2012 Jul 21;380(9838):294-305. Available from: http://www.ncbi.nlm.nih.gov/pubmed/22818941

[194] WHO. Global health risks : mortality and burden of disease attributable to selected major risks [Internet]. 2009. 62 p. Available from: https://apps.who.int/iris/handle/10665/44203

[195] Quindry JC, Hamilton KL. Exercise and cardiac preconditioning against ischemia reperfusion injury. Curr Cardiol Rev [Internet]. 2013 Aug;9(3):220-9. Available from: http://www.ncbi.nlm.nih.gov/pubmed/23909636

[196] Downey JM. Free radicals and their involvement during long-term myocardial ischemia and reperfusion. Annu Rev Physiol [Internet]. 1990;52:487-504. Available from: http://www.ncbi.nlm.nih.gov/pubmed/2184765

[197] Yellon DM, Hausenloy DJ. Myocardial reperfusion injury. N Engl J Med [Internet]. 2007 Sep 13;357(11):1121-35. Available from: http://www.ncbi.nlm.nih.gov/pubmed/17855673 
1 [198] Murry CE, Jennings RB, Reimer KA. Preconditioning with ischemia: a delay of lethal cell injury in ischemic myocardium. Circulation [Internet]. 1986 Nov;74(5):1124-36. Available from: http://www.ncbi.nlm.nih.gov/pubmed/3769170

[199] Bowles DK, Farrar RP, Starnes JW. Exercise training improves cardiac function after ischemia in the isolated, working rat heart. Am J Physiol [Internet]. 1992 Sep;263(3 Pt 2):H804-9. Available from: http://www.ncbi.nlm.nih.gov/pubmed/1415606

[200] Hoshida S, Yamashita N, Otsu K, Hori M. Repeated physiologic stresses provide persistent cardioprotection against ischemia-reperfusion injury in rats. J Am Coll Cardiol [Internet]. 2002 Aug 21;40(4):826-31. Available from: http://www.ncbi.nlm.nih.gov/pubmed/12204517

[201] Libonati JR, Gaughan JP, Hefner CA, Gow A, Paolone AM, Houser SR. Reduced ischemia and reperfusion injury following exercise training. Med Sci Sports Exerc [Internet]. 1997 Apr;29(4):509-16. Available from: http://www.ncbi.nlm.nih.gov/pubmed/9107634

[202] Quindry JC, Schreiber L, Hosick P, Wrieden J, Irwin JM, Hoyt E. Mitochondrial KATP channel inhibition blunts arrhythmia protection in ischemic exercised hearts. Am J Physiol Heart Circ Physiol [Internet]. 2010 Jul;299(1):H175-83. Available from: http://www.ncbi.nlm.nih.gov/pubmed/20435852

[203] DeVan AE, Umpierre D, Lin H-F, Harrison ML, Tarumi T, Dhindsa M, et al. Habitual resistance exercise and endothelial ischemia-reperfusion injury in young adults. Atherosclerosis [Internet]. 2011 Nov;219(1):191-3. Available from: http://www.ncbi.nlm.nih.gov/pubmed/21840524

[204] Maessen MFH, van Mil ACCM, Straathof Y, Riksen NP, Rongen GAPJM, Hopman MTE, et al. Impact of lifelong exercise training on endothelial ischemia-reperfusion and ischemic preconditioning in humans. Am J Physiol Regul Integr Comp Physiol [Internet]. 2017;312(5):R828-34. Available from: 
http://www.ncbi.nlm.nih.gov/pubmed/28298332

[205] Campos JC, Queliconi BB, Dourado PMM, Cunha TF, Zambelli VO, Bechara LRG, et al. Exercise training restores cardiac protein quality control in heart failure. PLoS One [Internet]. 2012;7(12):e52764. Available from: http://www.ncbi.nlm.nih.gov/pubmed/23300764

[206] Gibb AA, Epstein PN, Uchida S, Zheng Y, McNally LA, Obal D, et al. Exercise-Induced Changes in Glucose Metabolism Promote Physiological Cardiac Growth. Circulation [Internet]. 2017 Nov 28;136(22):2144-57. Available from: http://www.ncbi.nlm.nih.gov/pubmed/28860122

[207] Kavazis AN, Alvarez S, Talbert E, Lee Y, Powers SK. Exercise training induces a cardioprotective phenotype and alterations in cardiac subsarcolemmal and intermyofibrillar mitochondrial proteins. Am J Physiol Heart Circ Physiol [Internet]. $2009 \mathrm{Jul} ; 297(1): H 144-52$. Available from: http://www.ncbi.nlm.nih.gov/pubmed/19429812

[208] French JP, Hamilton KL, Quindry JC, Lee Y, Upchurch PA, Powers SK. Exerciseinduced protection against myocardial apoptosis and necrosis: MnSOD, calciumhandling proteins, and calpain. FASEB J [Internet]. 2008 Aug;22(8):2862-71. Available from: http://www.ncbi.nlm.nih.gov/pubmed/18417547

[209] Quindry J, French J, Hamilton K, Lee Y, Mehta JL, Powers S. Exercise training provides cardioprotection against ischemia-reperfusion induced apoptosis in young and old animals. Exp Gerontol [Internet]. 2005 May;40(5):416-25. Available from: http://www.ncbi.nlm.nih.gov/pubmed/15919594

[210] da Silva MF, Natali AJ, da Silva E, Gomes GJ, Teodoro BG, Cunha DNQ, et al. Attenuation of $\mathrm{Ca} 2+$ homeostasis, oxidative stress, and mitochondrial dysfunctions in diabetic rat heart: insulin therapy or aerobic exercise? J Appl Physiol (Bethesda, Md 1985) [Internet]. 2015 Jul 15;119(2):148-56. Available from: 
http://www.ncbi.nlm.nih.gov/pubmed/25997948

[211] Ascensão A, Lumini-Oliveira J, Machado NG, Ferreira RM, Gonçalves IO, Moreira AC, et al. Acute exercise protects against calcium-induced cardiac mitochondrial permeability transition pore opening in doxorubicin-treated rats. Clin Sci (London, Engl 1979) [Internet]. 2011 Jan;120(1):37-49. Available from: http://www.ncbi.nlm.nih.gov/pubmed/20666733

[212] Powers SK, Sollanek KJ, Wiggs MP, Demirel HA, Smuder AJ. Exercise-induced improvements in myocardial antioxidant capacity: the antioxidant players and cardioprotection. Free Radic Res [Internet]. 2014 Jan;48(1):43-51. Available from: http://www.ncbi.nlm.nih.gov/pubmed/23915097

[213] Hamilton KL, Quindry JC, French JP, Staib J, Hughes J, Mehta JL, et al. MnSOD antisense treatment and exercise-induced protection against arrhythmias. Free Radic Biol Med [Internet]. 2004 Nov 1;37(9):1360-8. Available from: http://www.ncbi.nlm.nih.gov/pubmed/15454275

[214] Ascensão A, Magalhães J, Soares JMC, Ferreira R, Neuparth MJ, Marques F, et al. Moderate endurance training prevents doxorubicin-induced in vivo mitochondriopathy and reduces the development of cardiac apoptosis. Am J Physiol Heart Circ Physiol [Internet]. 2005 Aug;289(2):H722-31. Available from: http://www.ncbi.nlm.nih.gov/pubmed/15792986

[215] Martin JL, Mestril R, Hilal-Dandan R, Brunton LL, Dillmann WH. Small heat shock proteins and protection against ischemic injury in cardiac myocytes. Circulation [Internet]. 1997 Dec 16;96(12):4343-8. Available from: http://www.ncbi.nlm.nih.gov/pubmed/9416902

[216] Rinaldi B, Corbi G, Boccuti S, Filippelli W, Rengo G, Leosco D, et al. Exercise training affects age-induced changes in SOD and heat shock protein expression in rat heart. Exp Gerontol [Internet]. 2006 Aug;41(8):764-70. Available from: 
http://www.ncbi.nlm.nih.gov/pubmed/16822632

[217] Chen K, Pittman RN, Popel AS. Nitric oxide in the vasculature: where does it come from and where does it go? A quantitative perspective. Antioxid Redox Signal [Internet]. 2008 Jul;10(7):1185-98. Available from: http://www.ncbi.nlm.nih.gov/pubmed/18331202

[218] Hambrecht R, Adams V, Erbs S, Linke A, Kränkel N, Shu Y, et al. Regular physical activity improves endothelial function in patients with coronary artery disease by increasing phosphorylation of endothelial nitric oxide synthase. Circulation [Internet]. 2003 Jul 1;107(25):3152-8. Available from: http://www.ncbi.nlm.nih.gov/pubmed/12810615

[219] Borniquel S, Valle I, Cadenas S, Lamas S, Monsalve M. Nitric oxide regulates mitochondrial oxidative stress protection via the transcriptional coactivator PGC-1alpha. FASEB J [Internet]. 2006 Sep;20(11):1889-91. Available from: http://www.ncbi.nlm.nih.gov/pubmed/16891621

[220] Nisoli E, Falcone S, Tonello C, Cozzi V, Palomba L, Fiorani M, et al. Mitochondrial biogenesis by NO yields functionally active mitochondria in mammals. Proc Natl Acad Sci U S A [Internet]. 2004 Nov 23;101(47):16507-12. Available from: http://www.ncbi.nlm.nih.gov/pubmed/15545607

[221] Subbotina E, Sierra A, Zhu Z, Gao Z, Koganti SRK, Reyes S, et al. Musclin is an activity-stimulated myokine that enhances physical endurance. Proc Natl Acad Sci U S A [Internet]. 2015 Dec 29;112(52):16042-7. Available from: http://www.ncbi.nlm.nih.gov/pubmed/26668395

[222] Willich SN, Lewis M, Löwel H, Arntz HR, Schubert F, Schröder R. Physical exertion as a trigger of acute myocardial infarction. Triggers and Mechanisms of Myocardial Infarction Study Group. N Engl J Med [Internet]. 1993 Dec 2;329(23):1684-90. Available from: http://www.ncbi.nlm.nih.gov/pubmed/8232457 
1 [223] Kavazis AN. Exercise preconditioning of the myocardium. Sports Med [Internet]. 2009;39(11):923-35. Available from: http://www.ncbi.nlm.nih.gov/pubmed/19827860

[224] Siasos G, Tsigkou V, Kosmopoulos M, Theodosiadis D, Simantiris S, Tagkou NM, et al. Mitochondria and cardiovascular diseases-from pathophysiology to treatment. Ann Transl Med [Internet]. 2018 Jun;6(12):256. Available from: http://www.ncbi.nlm.nih.gov/pubmed/30069458

[225] Bayeva M, Gheorghiade M, Ardehali H. Mitochondria as a therapeutic target in heart failure. J Am Coll Cardiol [Internet]. 2013 Feb 12;61(6):599-610. Available from: http://www.ncbi.nlm.nih.gov/pubmed/23219298

[226] Papageorgiou N, Tousoulis D, Katsargyris A, Charakida M, Androulakis E, Siasos G, et al. Antioxidant treatment and endothelial dysfunction: is it time for flavonoids? Recent Pat Cardiovasc Drug Discov [Internet]. 2013 Aug;8(2):81-92. Available from: http://www.ncbi.nlm.nih.gov/pubmed/23952809

[227] Papageorgiou N, Tousoulis D, Androulakis E, Giotakis A, Siasos G, Latsios G, et al. Lifestyle factors and endothelial function. Curr Vasc Pharmacol [Internet]. 2012 Jan;10(1):94-106. Available from: http://www.ncbi.nlm.nih.gov/pubmed/22112355

[228] Mercer JR. Mitochondrial bioenergetics and therapeutic intervention in cardiovascular disease. Pharmacol Ther [Internet]. 2014 Jan;141(1):13-20. Available from: http://www.ncbi.nlm.nih.gov/pubmed/23911986

[229] Bozaykut P, Karademir B, Yazgan B, Sozen E, Siow RCM, Mann GE, et al. Effects of vitamin $\mathrm{E}$ on peroxisome proliferator-activated receptor $\gamma$ and nuclear factor-erythroid 2related factor 2 in hypercholesterolemia-induced atherosclerosis. Free Radic Biol Med [Internet]. 2014 May;70:174-81. Available from: http://www.ncbi.nlm.nih.gov/pubmed/24583459

[230] Garrido-Maraver J, Cordero MD, Oropesa-Avila M, Vega AF, de la Mata M, Pavon AD, 
et al. Clinical applications of coenzyme Q10. Front Biosci (Landmark Ed [Internet]. 2014 Jan 1;19:619-33. Available from: http://www.ncbi.nlm.nih.gov/pubmed/24389208

[231] Graham D, Huynh NN, Hamilton CA, Beattie E, Smith RAJ, Cochemé HM, et al. Mitochondria-targeted antioxidant MitoQ10 improves endothelial function and attenuates cardiac hypertrophy. Hypertens (Dallas, Tex 1979) [Internet]. 2009 Aug;54(2):322-8. Available from: http://www.ncbi.nlm.nih.gov/pubmed/19581509

[232] Littarru GP, Langsjoen P. Coenzyme Q10 and statins: biochemical and clinical implications. Mitochondrion [Internet]. 2007 Jun;7 Suppl:S168-74. Available from: http://www.ncbi.nlm.nih.gov/pubmed/17482884

[233] Pepe S, Marasco SF, Haas SJ, Sheeran FL, Krum H, Rosenfeldt FL. Coenzyme Q10 in cardiovascular disease. Mitochondrion [Internet]. 2007 Jun;7 Suppl:S154-67. Available from: http://www.ncbi.nlm.nih.gov/pubmed/17485243

[234] Smith RA, Porteous CM, Coulter C V, Murphy MP. Selective targeting of an antioxidant to mitochondria. Eur J Biochem [Internet]. 1999 Aug;263(3):709-16. Available from: http://www.ncbi.nlm.nih.gov/pubmed/10469134

[235] Adlam VJ, Harrison JC, Porteous CM, James AM, Smith RAJ, Murphy MP, et al. Targeting an antioxidant to mitochondria decreases cardiac ischemia-reperfusion injury. FASEB J [Internet]. 2005 Jul;19(9):1088-95. Available from: http://www.ncbi.nlm.nih.gov/pubmed/15985532

[236] McLachlan J, Beattie E, Murphy MP, Koh-Tan CHH, Olson E, Beattie W, et al. Combined therapeutic benefit of mitochondria-targeted antioxidant, MitoQ10, and angiotensin receptor blocker, losartan, on cardiovascular function. J Hypertens [Internet]. 2014 Mar;32(3):555-64. Available from: http://www.ncbi.nlm.nih.gov/pubmed/24309493

[237] Reily C, Mitchell T, Chacko BK, Benavides G, Murphy MP, Darley-Usmar V. 
Mitochondrially targeted compounds and their impact on cellular bioenergetics. Redox Biol [Internet]. 2013;1(1):86-93. Available from: http://www.ncbi.nlm.nih.gov/pubmed/23667828

[238] Cochemé HM, Quin C, McQuaker SJ, Cabreiro F, Logan A, Prime TA, et al. Measurement of $\mathrm{H} 2 \mathrm{O} 2$ within living Drosophila during aging using a ratiometric mass spectrometry probe targeted to the mitochondrial matrix. Cell Metab [Internet]. 2011 Mar 2;13(3):340-50. Available from: http://www.ncbi.nlm.nih.gov/pubmed/21356523

[239] Robinson KM, Janes MS, Pehar M, Monette JS, Ross MF, Hagen TM, et al. Selective fluorescent imaging of superoxide in vivo using ethidium-based probes. Proc Natl Acad Sci U S A [Internet]. 2006 Oct 10;103(41):15038-43. Available from: http://www.ncbi.nlm.nih.gov/pubmed/17015830

[240] Prime TA, Forkink M, Logan A, Finichiu PG, McLachlan J, Li Pun PB, et al. A ratiometric fluorescent probe for assessing mitochondrial phospholipid peroxidation within living cells. Free Radic Biol Med [Internet]. 2012 Aug 1;53(3):544-53. Available from: http://www.ncbi.nlm.nih.gov/pubmed/22659314

[241] Prime TA, Blaikie FH, Evans C, Nadtochiy SM, James AM, Dahm CC, et al. A mitochondria-targeted S-nitrosothiol modulates respiration, nitrosates thiols, and protects against ischemia-reperfusion injury. Proc Natl Acad Sci U S A [Internet]. 2009 Jun 30;106(26):10764-9. Available from: http://www.ncbi.nlm.nih.gov/pubmed/19528654

[242] Pucheu S, Boucher F, Sulpice T, Tresallet N, Bonhomme Y, Malfroy B, et al. EUK-8 a synthetic catalytic scavenger of reactive oxygen species protects isolated iron-overloaded rat heart from functional and structural damage induced by ischemia/reperfusion. Cardiovasc drugs Ther [Internet]. $1996 \mathrm{Jul}$;10(3):331-9. Available from: http://www.ncbi.nlm.nih.gov/pubmed/8877076

[243] Cheng J, Kamiya K, Kodama I. Carvedilol: molecular and cellular basis for its multifaceted therapeutic potential. Cardiovasc Drug Rev [Internet]. 2001;19(2):152-71. 
Available from: http://www.ncbi.nlm.nih.gov/pubmed/11484068

[244] Pereira GC, Silva AM, Diogo C V, Carvalho FS, Monteiro P, Oliveira PJ. Drug-induced cardiac mitochondrial toxicity and protection: from doxorubicin to carvedilol. Curr Pharm Des [Internet]. 2011;17(20):2113-29. Available from: http://www.ncbi.nlm.nih.gov/pubmed/21718248

[245] Oliveira PJ, Esteves T, Rolo AP, Palmeira CM, Moreno AJM. Carvedilol inhibits the mitochondrial permeability transition by an antioxidant mechanism. Cardiovasc Toxicol [Internet]. 2004;4(1):11-20. Available from: http://www.ncbi.nlm.nih.gov/pubmed/15034201

[246] Oliveira PJ, Rolo AP, Palmeira CM, Moreno AJ. Carvedilol reduces mitochondrial damage induced by hypoxanthine/xanthine oxidase: relevance to hypoxia/reoxygenation injury. Cardiovasc Toxicol [Internet]. 2001;1(3):205-13. Available from: http://www.ncbi.nlm.nih.gov/pubmed/12213973

[247] Oliveira PJ, Coxito PM, Rolo AP, Santos DL, Palmeira CM, Moreno AJ. Inhibitory effect of carvedilol in the high-conductance state of the mitochondrial permeability transition pore. Eur J Pharmacol [Internet]. 2001 Feb 2;412(3):231-7. Available from: http://www.ncbi.nlm.nih.gov/pubmed/11166286

[248] Oliveira PJ, Bjork JA, Santos MS, Leino RL, Froberg MK, Moreno AJ, et al. Carvedilolmediated antioxidant protection against doxorubicin-induced cardiac mitochondrial toxicity. Toxicol Appl Pharmacol [Internet]. 2004 Oct 15;200(2):159-68. Available from: http://www.ncbi.nlm.nih.gov/pubmed/15476868

[249] Sgobbo P, Pacelli C, Grattagliano I, Villani G, Cocco T. Carvedilol inhibits mitochondrial complex I and induces resistance to $\mathrm{H} 2 \mathrm{O} 2$-mediated oxidative insult in H9C2 myocardial cells. Biochim Biophys Acta [Internet]. 2007 Mar;1767(3):222-32. Available from: http://www.ncbi.nlm.nih.gov/pubmed/17346667 
[250] Cheema Y, Sherrod JN, Zhao W, Zhao T, Ahokas RA, Sun Y, et al. Mitochondriocentric pathway to cardiomyocyte necrosis in aldosteronism: cardioprotective responses to carvedilol and nebivolol. J Cardiovasc Pharmacol [Internet]. 2011 Jul;58(1):80-6. Available from: http://www.ncbi.nlm.nih.gov/pubmed/21558884

[251] Bjelakovic G, Nikolova D, Gluud LL, Simonetti RG, Gluud C. Antioxidant supplements for prevention of mortality in healthy participants and patients with various diseases. Sao Paulo Med J [Internet]. 2015;133(2):164-5. Available from: http://www.ncbi.nlm.nih.gov/pubmed/26018887

[252] Sanbe A, Tanonaka K, Kobayasi R, Takeo S. Effects of long-term therapy with ACE inhibitors, captopril, enalapril and trandolapril, on myocardial energy metabolism in rats with heart failure following myocardial infarction. J Mol Cell Cardiol [Internet]. 1995 Oct;27(10):2209-22. Available from: http://www.ncbi.nlm.nih.gov/pubmed/8576937

[253] de Cavanagh EM V, Toblli JE, Ferder L, Piotrkowski B, Stella I, Inserra F. Renal mitochondrial dysfunction in spontaneously hypertensive rats is attenuated by losartan but not by amlodipine. Am J Physiol Regul Integr Comp Physiol [Internet]. 2006 Jun;290(6):R1616-25. Available from: http://www.ncbi.nlm.nih.gov/pubmed/16410402

[254] Vogiatzi G, Oikonomou E, Siasos G, Tsalamandris S, Briasoulis A, Androulakis E, et al. Statins and inflammation in cardiovascular disease. Curr Pharm Des [Internet]. 2017 Oct 9; Available from: http://www.ncbi.nlm.nih.gov/pubmed/28990524

[255] Tousoulis D, Oikonomou E, Siasos G, Chrysohoou C, Zaromitidou M, Kioufis S, et al. Dose-dependent effects of short term atorvastatin treatment on arterial wall properties and on indices of left ventricular remodeling in ischemic heart failure. Atherosclerosis [Internet]. 2013 Apr;227(2):367-72. Available from: http://www.ncbi.nlm.nih.gov/pubmed/23433403

[256] Costa S, Reina-Couto M, Albino-Teixeira A, Sousa T. Statins and oxidative stress in chronic heart failure. Rev Port Cardiol [Internet]. 2016 Jan;35(1):41-57. Available from: 
http://www.ncbi.nlm.nih.gov/pubmed/26763895

[257] Parihar A, Parihar MS, Zenebe WJ, Ghafourifar P. Statins lower calcium-induced oxidative stress in isolated mitochondria. Hum Exp Toxicol [Internet]. 2012 Apr;31(4):355-63. Available from: http://www.ncbi.nlm.nih.gov/pubmed/22144727

[258] Tousoulis D, Koniari K, Antoniades C, Papageorgiou N, Miliou A, Noutsou M, et al. Combined effects of atorvastatin and metformin on glucose-induced variations of inflammatory process in patients with diabetes mellitus. Int J Cardiol [Internet]. 2011 May 19;149(1):46-9. Available from: http://www.ncbi.nlm.nih.gov/pubmed/20034685

[259] Cahova M, Palenickova E, Dankova H, Sticova E, Burian M, Drahota Z, et al. Metformin prevents ischemia reperfusion-induced oxidative stress in the fatty liver by attenuation of reactive oxygen species formation. Am J Physiol Gastrointest Liver Physiol [Internet]. 2015 Jul 15;309(2):G100-11. Available from: http://www.ncbi.nlm.nih.gov/pubmed/26045616

[260] Hauner H. The mode of action of thiazolidinediones. Diabetes Metab Res Rev [Internet]. 2002;18 Suppl 2:S10-5. Available from: http://www.ncbi.nlm.nih.gov/pubmed/11921433

[261] Hernanz R, Martín Á, Pérez-Girón J V, Palacios R, Briones AM, Miguel M, et al. Pioglitazone treatment increases COX-2-derived prostacyclin production and reduces oxidative stress in hypertensive rats: role in vascular function. Br J Pharmacol [Internet]. 2012 Jun;166(4):1303-19. Available from: http://www.ncbi.nlm.nih.gov/pubmed/22220498

[262] Szeto HH. First-in-class cardiolipin-protective compound as a therapeutic agent to restore mitochondrial bioenergetics. Br J Pharmacol [Internet]. 2014 Apr;171(8):2029_ 50. Available from: http://www.ncbi.nlm.nih.gov/pubmed/24117165

[263] Sabbah HN, Gupta RC, Kohli S, Wang M, Hachem S, Zhang K. Chronic Therapy With 
Elamipretide (MTP-131), a Novel Mitochondria-Targeting Peptide, Improves Left Ventricular and Mitochondrial Function in Dogs With Advanced Heart Failure. Circ Heart Fail [Internet]. 2016 Feb;9(2):e002206. Available from: http://www.ncbi.nlm.nih.gov/pubmed/26839394

[264] Daubert MA, Yow E, Dunn G, Marchev S, Barnhart H, Douglas PS, et al. Novel Mitochondria-Targeting Peptide in Heart Failure Treatment: A Randomized, PlaceboControlled Trial of Elamipretide. Circ Heart Fail [Internet]. 2017 Dec;10(12):e004389. Available from: http://www.ncbi.nlm.nih.gov/pubmed/29217757

[265] See F, Thomas W, Way K, Tzanidis A, Kompa A, Lewis D, et al. p38 mitogen-activated protein kinase inhibition improves cardiac function and attenuates left ventricular remodeling following myocardial infarction in the rat. J Am Coll Cardiol [Internet]. 2004 Oct 19;44(8):1679-89. Available from: http://www.ncbi.nlm.nih.gov/pubmed/15489104 


\section{Legends for figures}

2

3 Figure 1. Schematic diagram of the major CVD risk factors with in which an established

4 relation with disease development has been determined in multiple studies.

5 Figure 2. The contribution of altered metabolism in cardiovascular risk

6 Figure 3. Cardiac mitochondria are essential to maintain the energy supply required by 7 cardiomyocytes, especially for the contraction/relaxation process. In the inner 8 mitochondrial membrane, the four ETC complexes create a proton gradient that is used 9 to powers ATP synthase. ATP and $\mathrm{Ca}^{2+}$ are both required for the contraction process. 10 Most of ATP is consumed by ions pumps (including SERCA and $\mathrm{Ca}^{2+}$ ATPase) and 11 contractile myofilaments. The increase of $\mathrm{Ca}^{2+}$ on the cytosol activates contraction and 12 its release back to sarcoplasmic reticulum (SR) or the extracellular milieu leads to 13 relaxation. $\mathrm{Ca}^{2+}$ enters mitochondria through VDACs and mitochondrial $\mathrm{Ca}^{2+}$ uniporter 14 (MCU) complex and, when inside, it regulates ATP production and mitochondrial 15 homeostasis. ANT, adenine nucleotide translocase; OXPHOS, oxidative 16 phosphorylation.

Figure 4. NAFLD leads to the increase of fat deposit accumulation in the hepatocytes, leading to a decreased ability of hepatic mitochondria to oxidize fatty acids. Often associated with dyslipidemia, one consequence of NAFLD is increased oxidative stress

21 in other tissues, including the heart. Obesity, one risk factor for NAFLD, is often accompanied by increased lipid accumulation in the cardiac tissue and surrounding epicardial adipose tissue. 
1 Figure 5. Changes in cardiac mitochondria induced by obesity, aging, diabetes, NAFLD

2 and KD and risk of cardiovascular diseases. Several conditions such obesity, aging,

3 diabetes, NAFLD and KD disturb the system and induces changes in cardiac

4 mitochondrial function. The heart is a high-demand energy organ and relies, majority, on

5 mitochondrial function. Damages in cardiac mitochondrial function increases the

6 cardiovascular risk and may lead to HF.

7 Figure 6. Cardiovascular benefits of regular exercise and some pharmacological 8 interventions. 


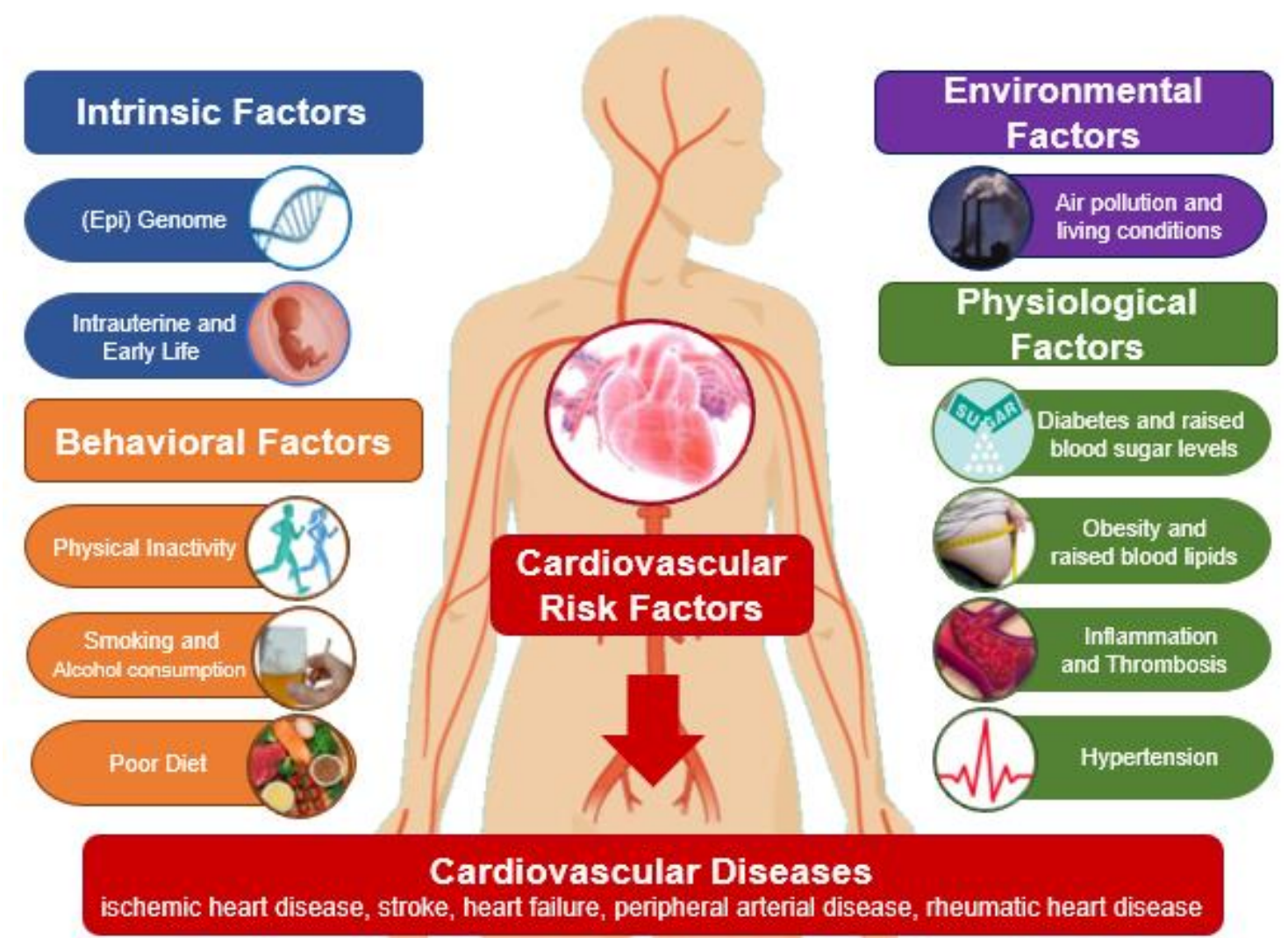




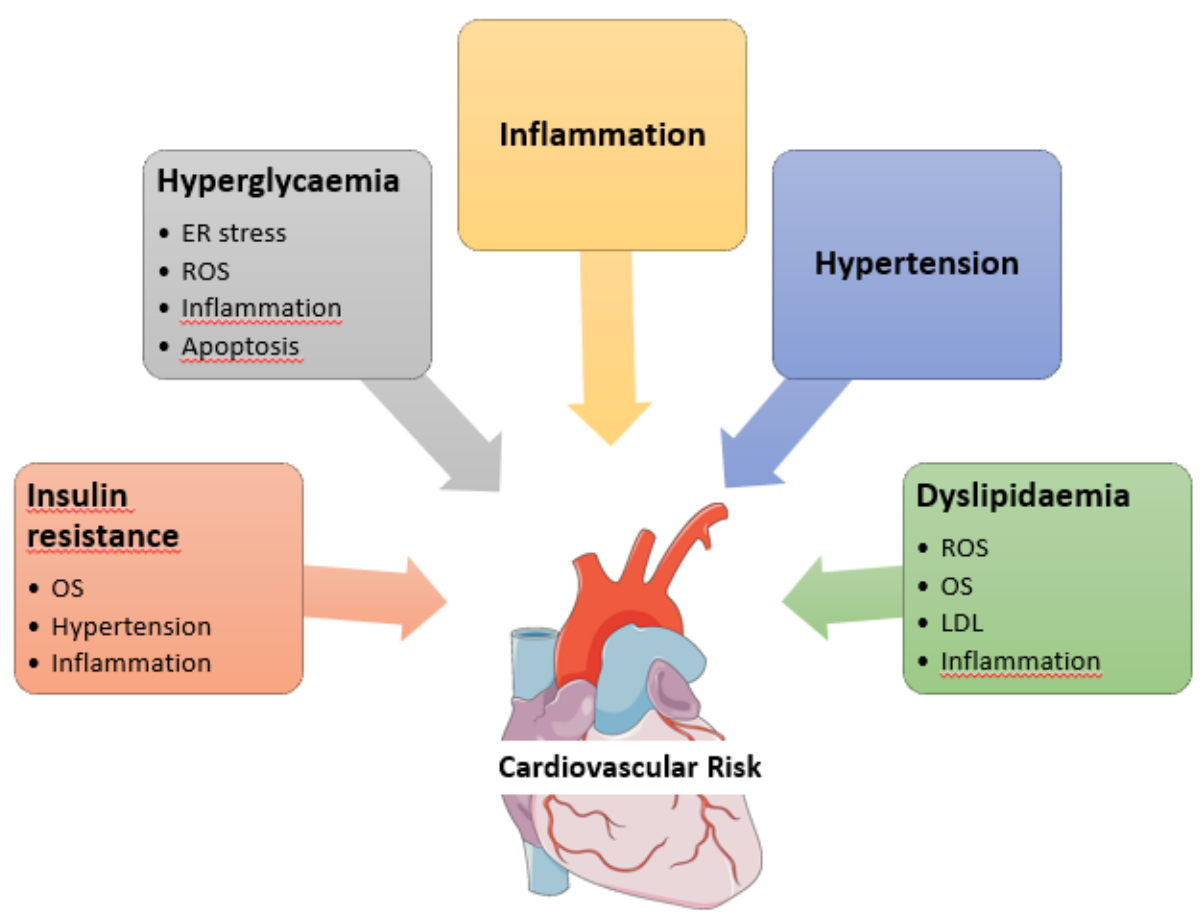

1 


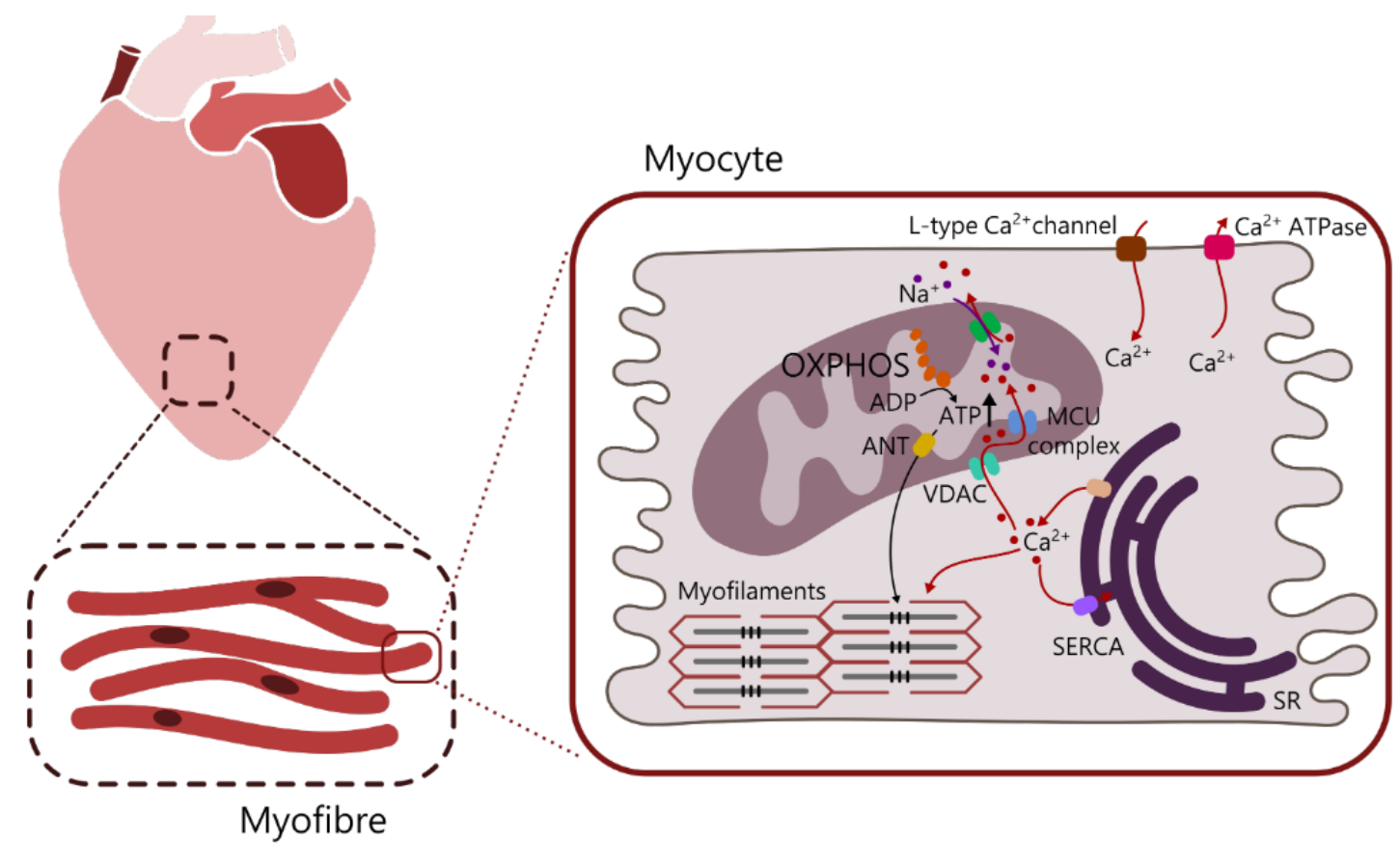




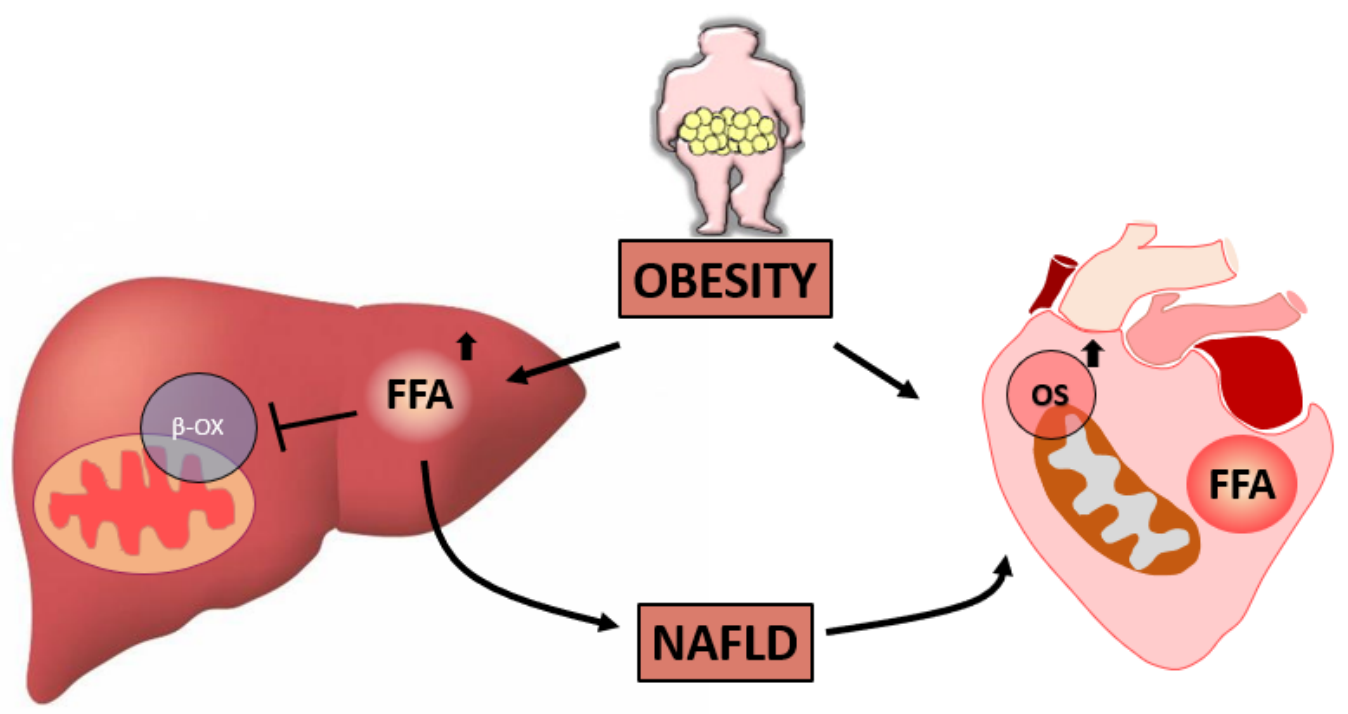

1 


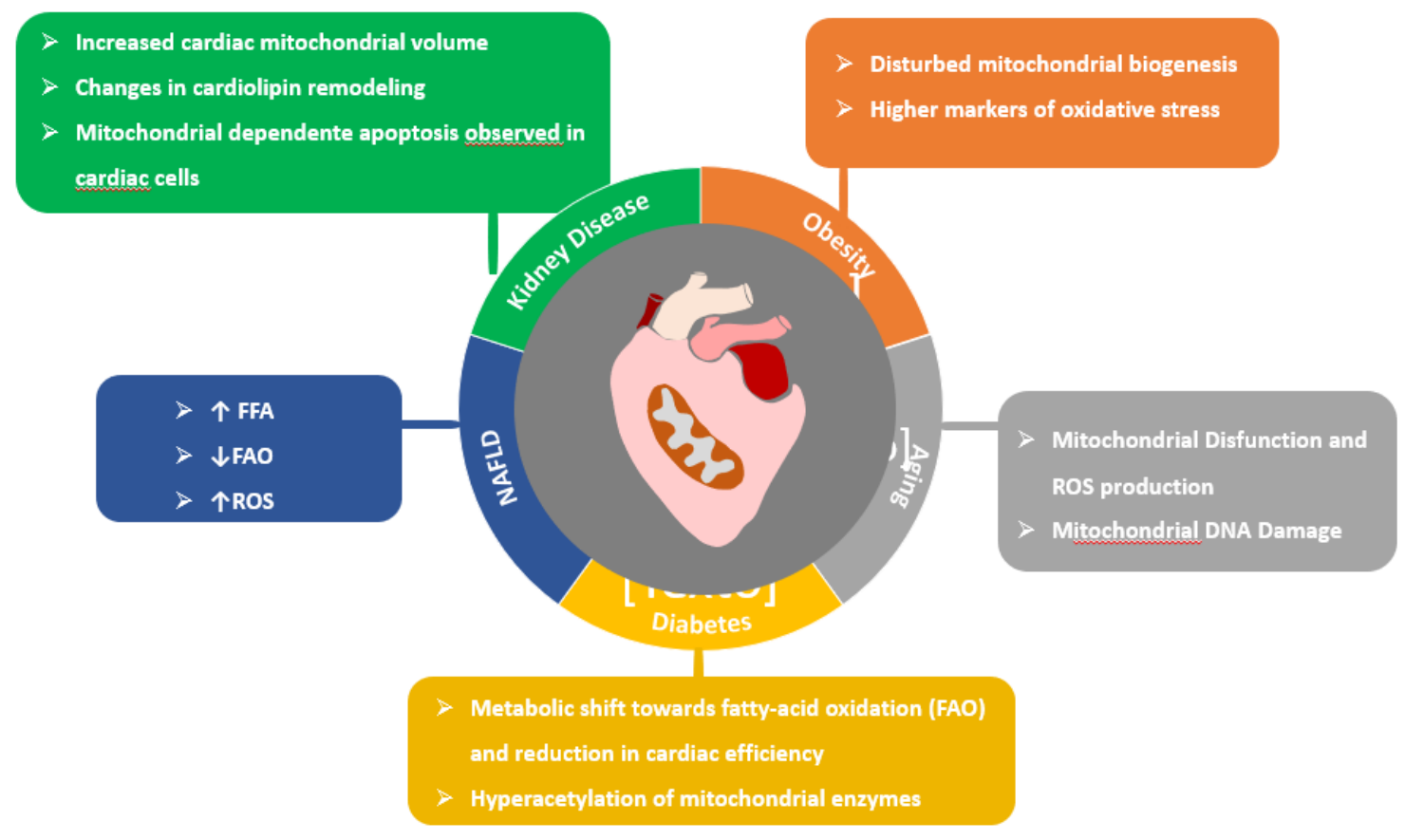



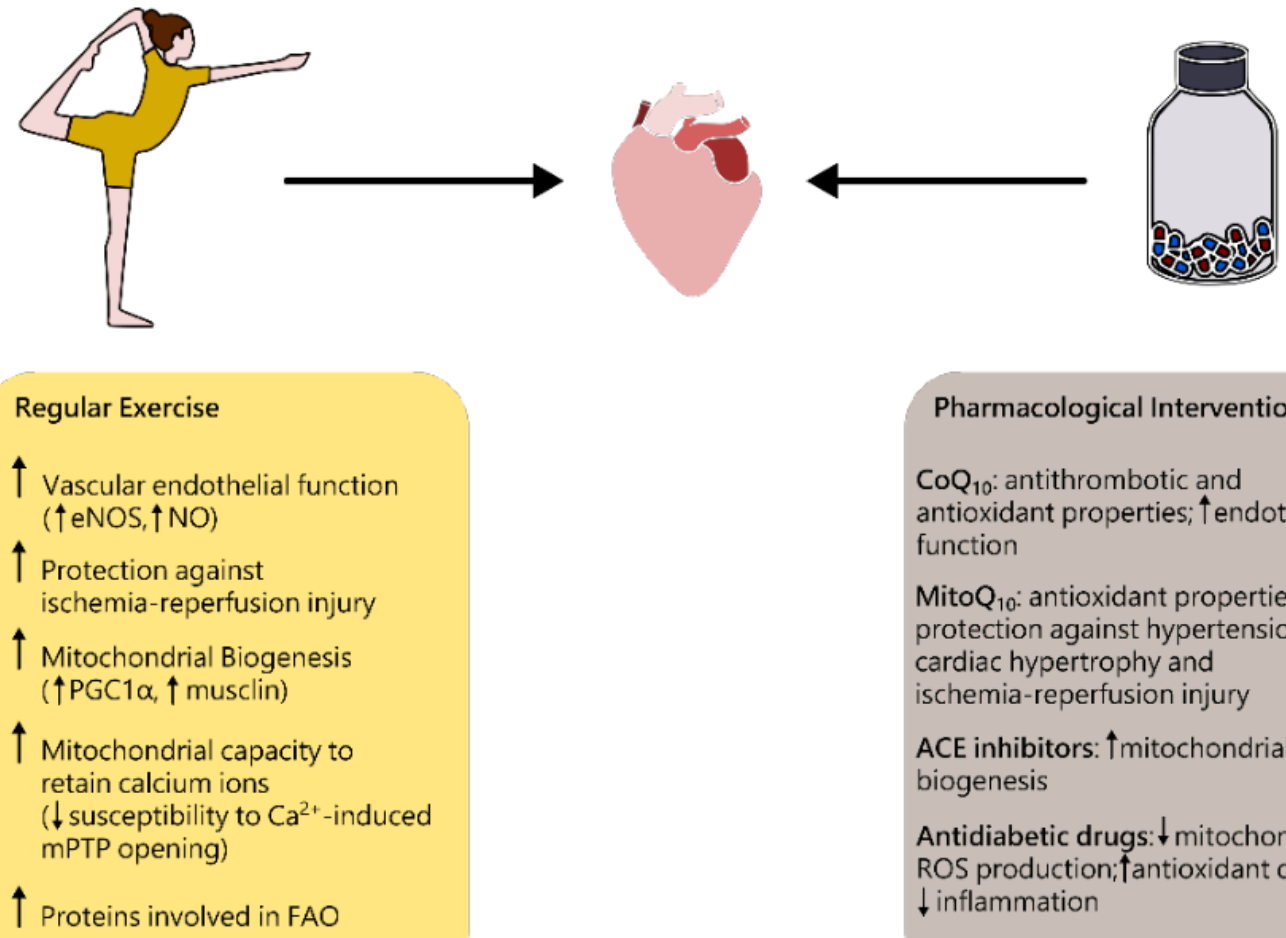

$\uparrow$ Proteins involved in FAO

\section{Pharmacological Interventions}

$\mathrm{CoQ}_{10}$ : antithrombotic and antioxidant properties; $\uparrow$ endothelial function

Mito $_{10}$ : antioxidant properties; protection against hypertension, cardiac hypertrophy and ischemia-reperfusion injury

ACE inhibitors: $\uparrow$ mitochondrial biogenesis

Antidiabetic drugs: $\downarrow$ mitochondrial ROS production; †antioxidant defenses; $\downarrow$ inflammation 